\title{
A benchmark for homomeric enzyme active site structure prediction highlights the importance of accurate modeling of protein symmetry.
}

Stephanie C. Contreras ${ }^{1}$, Steve J. Bertolani ${ }^{1}$, Justin B. Siegel ${ }^{1,2,3^{*}}$

1. Department of Chemistry, University of California, Davis, Davis, California, United States of America

2. Department of Biochemistry and Molecular Medicine, University of California, Davis, California, United States of America

3. Genome Center, University of California, Davis, Davis, California, United States of America

KEYWORDS: Structure prediction, Rosetta Molecular Modeling Suite, Protein Symmetry. 
Figure S1 Plot showing the $\mathrm{C}$ alpha distance deviation from the target crystal structure to their corresponding templates versus the template percent identity

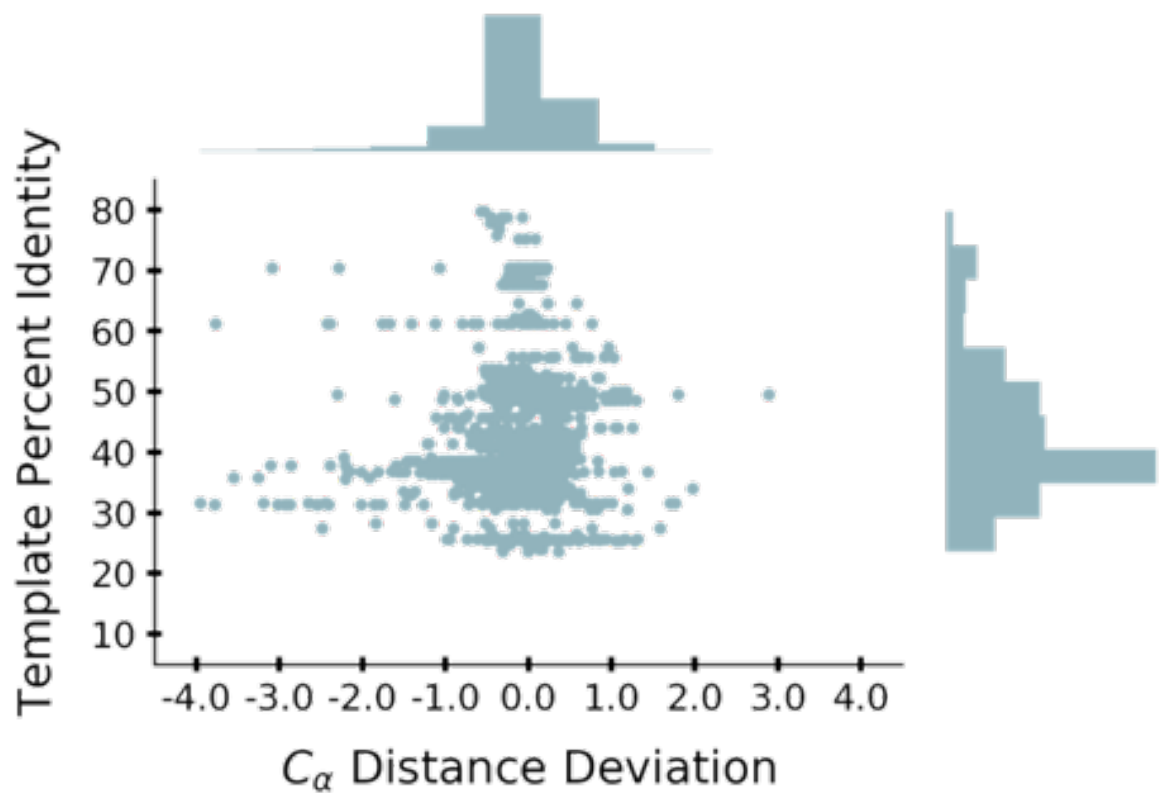

Figure S2 Visual representation as to how the distances used in the modeling were determined

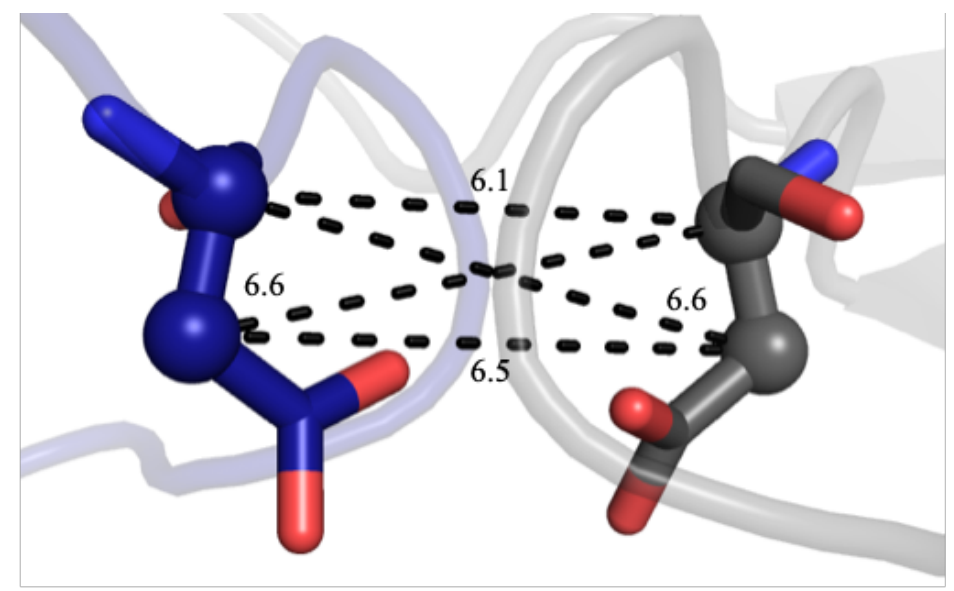

AtomPair CA 25 CA 124 SCALARWEIGHTEDFUNC 1 HARMONIC $6.08 \quad 0.6$

AtomPair CB 25 CB 124 SCALARWEIGHTEDFUNC 1 HARMONIC $6.64 \quad 0.7$

AtomPair CA 25 CB 124 SCALARWEIGHTEDFUNC 1 HARMONIC $6.57 \quad 0.7$

AtomPair CA 124 CB 25 SCALARWEIGHTEDFUNC 1 HARMONIC $6.50 \quad 0.7$ 


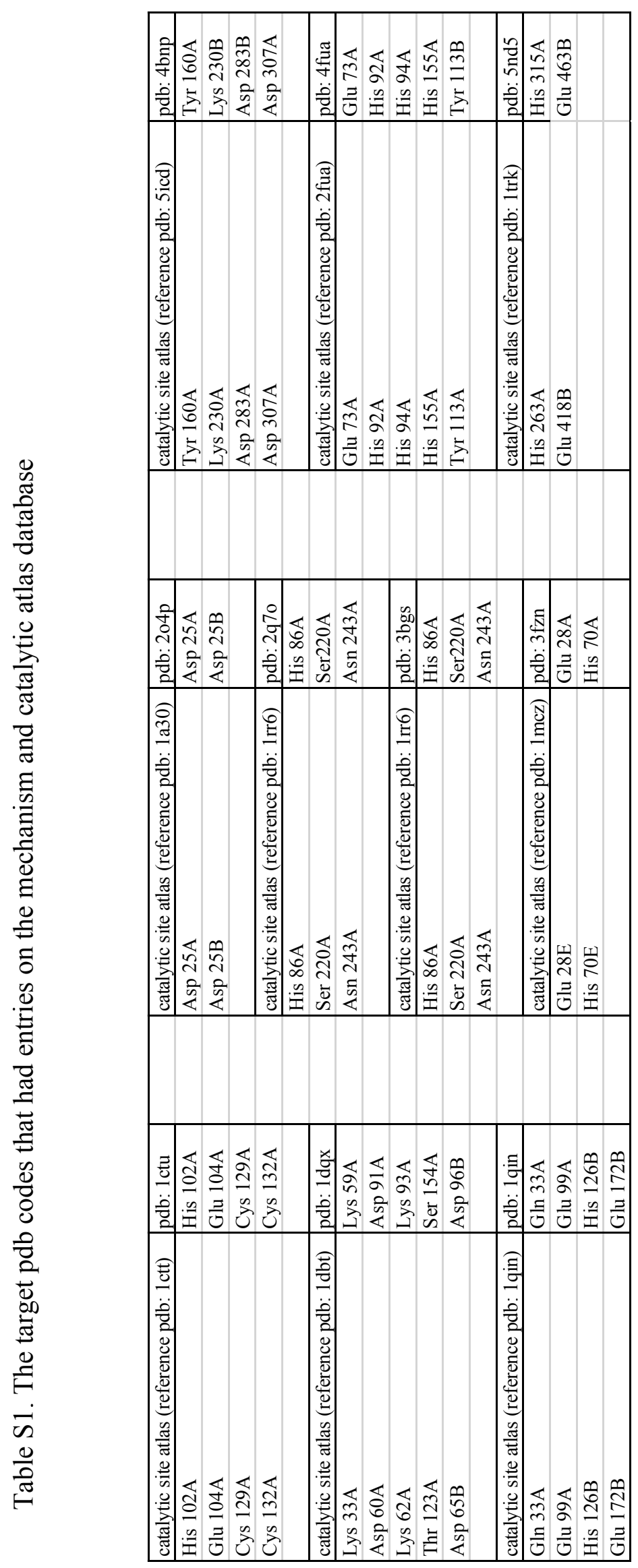


Table S2. The target pdb codes with the templates that were used for modeling

\begin{tabular}{|c|c|c|c|c|c|c|c|c|c|c|}
\hline Target & Templa & es used & & & & & & & & \\
\hline $1 \mathrm{ctu}$ & lux0 & lux1 & 1zab & $2 \mathrm{~d} 30$ & $3 \mathrm{dmo}$ & 3ijf & $3 \mathrm{r} 2 \mathrm{n}$ & $4 \mathrm{eg} 2$ & 4wif & 4wig \\
\hline $1 \mathrm{dqx}$ & 1 eix & 2eaw & 2jgy & $2 \mathrm{qcc}$ & $2 \mathrm{qcf}$ & 3bk0 & $3 b v j$ & 3ewx & $31 \mathrm{dv}$ & $3 \operatorname{tr} 2$ \\
\hline 1nki & $1 \mathrm{npb}$ & $1 \mathrm{r} 9 \mathrm{c}$ & $2 p 7 q$ & 4ir0 & 4jh1 & 4nay & 4nb1 & $5 f 6 q$ & $5 v 3 d$ & $5 \mathrm{vb} 0$ \\
\hline 1ovm & $1 \mathrm{pvd}$ & 1pyd & $1 q p b$ & 1zpd & $2 \mathrm{vbf}$ & 2vjy & 2vk1 & $2 \mathrm{vk} 8$ & $2 \mathrm{w} 93$ & $4 \mathrm{cok}$ \\
\hline 1 qin & $1 \mathrm{f} 9 \mathrm{z}$ & $2 \mathrm{c} 21$ & 4hc5 & $4 \mathrm{mtq}$ & $5 \mathrm{~d} 7 \mathrm{z}$ & & & & & \\
\hline 1 a59 & 3hwk & $308 j$ & 3tqg & 1iom & 1ixe & & & & & \\
\hline $2 o 4 p$ & $2 \mathrm{p} 3 \mathrm{~d}$ & 3ggu & $3 \mathrm{mws}$ & $3 t 3 c$ & $3 \mathrm{ttp}$ & $3 \mathrm{u} 7 \mathrm{~s}$ & 3 ucb & $4 z 4 x$ & $5 b 18$ & $5 \mathrm{t} 2 \mathrm{e}$ \\
\hline $2 \mathrm{q} 7 \mathrm{o}$ & $1 \mathrm{tcu}$ & $1 \mathrm{vmk}$ & $2 \mathrm{p} 4 \mathrm{~s}$ & 3khs & 3la8 & 4lna & $4 \mathrm{~m} 1 \mathrm{e}$ & $5 \mathrm{cxq}$ & $5 \mathrm{cxs}$ & 5ifk \\
\hline $2 \mathrm{vbg}$ & 1ovm & $1 \mathrm{pvd}$ & 1pyd & $1 \mathrm{qpb}$ & 2vjy & 2vk1 & $2 \mathrm{vk} 8$ & 2 w93 & 4 cok & 5euj \\
\hline 3 bgs & 1 tcu & $1 \mathrm{vmk}$ & $2 \mathrm{p} 4 \mathrm{~s}$ & $3 \mathrm{khs}$ & 3la8 & 4lna & $4 \mathrm{~m} 1 \mathrm{e}$ & $5 \mathrm{cxq}$ & $5 \mathrm{cxs}$ & 5ifk \\
\hline 3 fuc & $1 \mathrm{tcu}$ & $2 \mathrm{p} 4 \mathrm{~s}$ & $3 \mathrm{khs}$ & $31 \mathrm{a} 8$ & 4lna & $4 \mathrm{~m} 1 \mathrm{e}$ & 4ns1 & $5 \mathrm{cxq}$ & $5 \mathrm{cxs}$ & 5 ifk \\
\hline 3 fzn & $1 \mathrm{jsc}$ & 2ag0 & 2pan & 2uz1 & $3 \mathrm{~d} 7 \mathrm{k}$ & 3 iae & $4 k 9 q$ & $4 q 9 d$ & $4 q p z$ & $5 \mathrm{fem}$ \\
\hline $3 \mathrm{mng}$ & 1 tp9 & $2 \mathrm{wfc}$ & $2 x h f$ & 3uma & $4 \mathrm{f} 82$ & $5 \mathrm{k} 1 \mathrm{~g}$ & $5 \mathrm{k} 2 \mathrm{i}$ & & & \\
\hline 4bnp & 1hqs & $1 \times 01$ & 1xkd & $2 \mathrm{~d} 4 \mathrm{v}$ & $2 \mathrm{dht}$ & 2iv0 & 3ah3 & 3asj & $3 \mathrm{dms}$ & \\
\hline 4fua & $1 \mathrm{jdi}$ & $1 \mathrm{k} 0 \mathrm{w}$ & $2 \mathrm{fk} 5$ & 2irp & 2opi & 3ocr & $4 \mathrm{c} 24$ & $4 c 25$ & $4 \mathrm{~m} 6 \mathrm{r}$ & $4 \times x f$ \\
\hline 4hgo & $1 \mathrm{j} 8 \mathrm{~d}$ & $2 r 8 x$ & $3 i 6 b$ & 3ij5 & $3 \mathrm{mmz}$ & $3 \mathrm{mn} 1$ & 3n07 & $3 n 1 u$ & 4nav & 4um5 \\
\hline 5nd5 & 1ay0 & 1gpu & $1 \mathrm{itz}$ & 1qgd & $1 \mathrm{r} 9 \mathrm{j}$ & $1 \mathrm{tka}$ & $2 \mathrm{e} 6 \mathrm{k}$ & $2 \mathrm{r} 8 \mathrm{o}$ & 3hyl & $5 \mathrm{hht}$ \\
\hline
\end{tabular}


Table S3. The target pdb codes with the number of chains the biological unit has and the corresponding top template used for modeling with the number of chains the biological unit the template has

\begin{tabular}{|c|c|c|c|c|}
\hline target & bio chains & top template & pid & bio chains \\
\hline $1 \mathrm{ctu}$ & 2 & 4eg2 & 48.6 & 2 \\
\hline $1 \mathrm{dqx}$ & 2 & $2 q c c$ & 52.3 & 2 \\
\hline 1nki & 2 & $5 v 3 d$ & 67.7 & 2 \\
\hline lovm & 4 & $2 \mathrm{vbf}$ & 41.4 & 2 \\
\hline 1qin & 2 & $4 \mathrm{mtq}$ & 42.1 & 2 \\
\hline $1 \mathrm{a} 59$ & 2 & 3hwk & 59.8 & 2 \\
\hline $2 o 4 p$ & 2 & $5 \mathrm{t} 2 \mathrm{e}$ & 79.8 & 2 \\
\hline $2 q 7 o$ & 3 & $2 \mathrm{p} 4 \mathrm{~s}$ & 55.8 & 3 \\
\hline $2 \mathrm{vbg}$ & 2 & lovm & 41.4 & 4 \\
\hline $3 \mathrm{bgs}$ & 3 & $2 \mathrm{p} 4 \mathrm{~s}$ & 55.8 & 3 \\
\hline 3 fuc & 3 & $2 \mathrm{p} 4 \mathrm{~s}$ & 55.6 & 3 \\
\hline $3 \mathrm{fzn}$ & 4 & $4 q 9 d$ & 44.5 & 4 \\
\hline $3 \mathrm{mng}$ & 2 & $2 w f c$ & 64.6 & 2 \\
\hline 4bnp & 2 & $3 \mathrm{dms}$ & 75.2 & 2 \\
\hline 4 fua & 4 & $4 c 24$ & 43.4 & 4 \\
\hline 4hgo & 4 & $3 \mathrm{mn} 1$ & 43.1 & 4 \\
\hline $5 \mathrm{nd} 5$ & 2 & litz & 68.5 & 2 \\
\hline
\end{tabular}


Table S4. Details about the sampling of the conformational library and constraints. The atoms in the ligands were allowed to sample all conformer space with the exception that contained the cofactor thiamine pyrophosphate. The pyrophosphate functional group atoms were frozen. The conformation library of the ligands generated was used to dock into the models.

\begin{tabular}{|l|l|}
\hline pdb code ligand & Description for conformational library \\
\hline $\begin{array}{l}\text { 1ovm, 2vbg, } \\
\text { 3fzn, 5nd5 }\end{array}$ & The pyrophosphate region was frozen \\
\hline 4hgo & $\begin{array}{l}\text { The vanadium was changed to a phosphorous atom because Rosetta does not have } \\
\text { that atom type in it's library }\end{array}$ \\
\hline
\end{tabular}



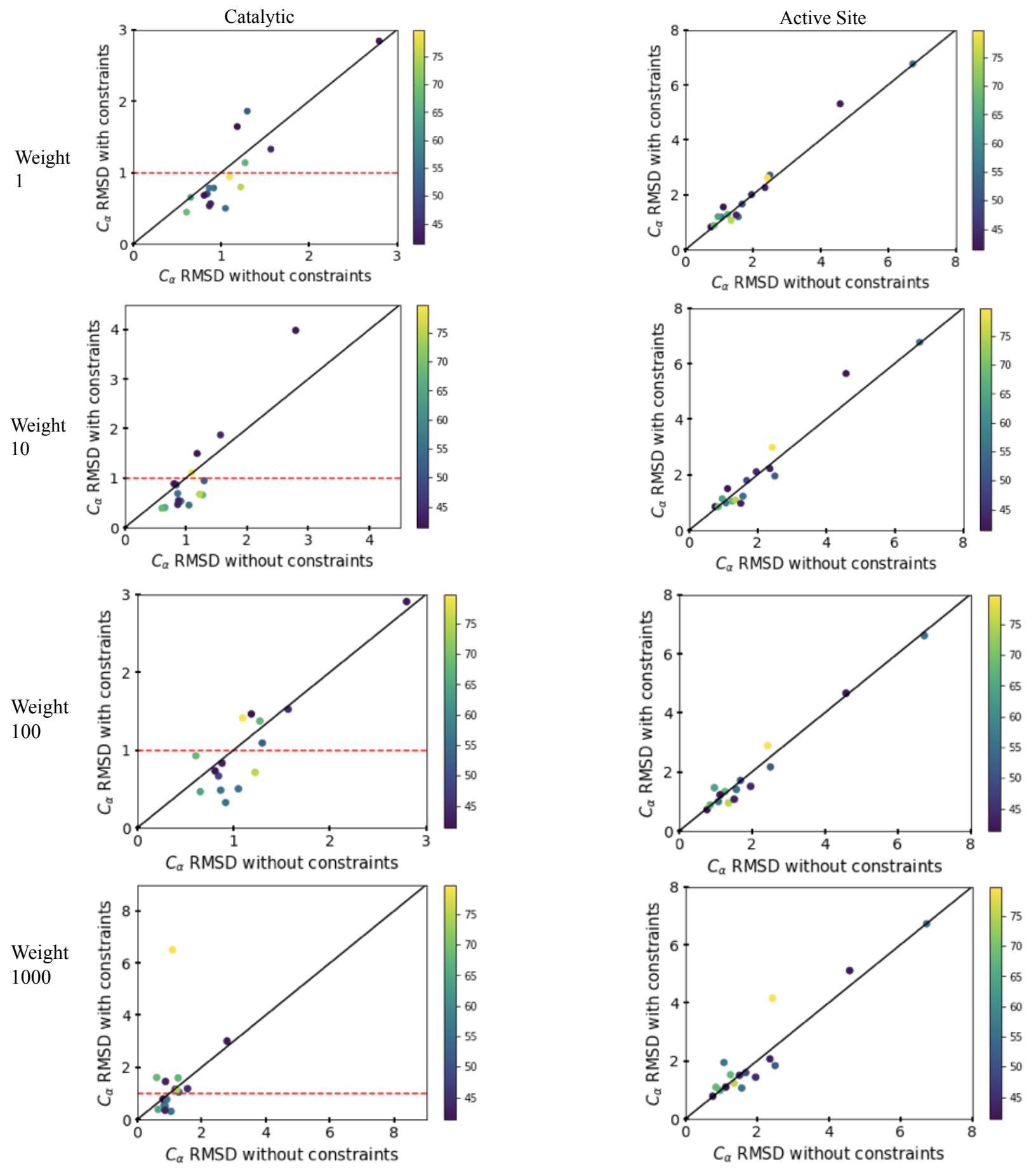

Figure S3 The analysis performed on the models with the weights of 1, 10, 100, 1000 
(A)

Models without catalytic constraints All Residue RMSD

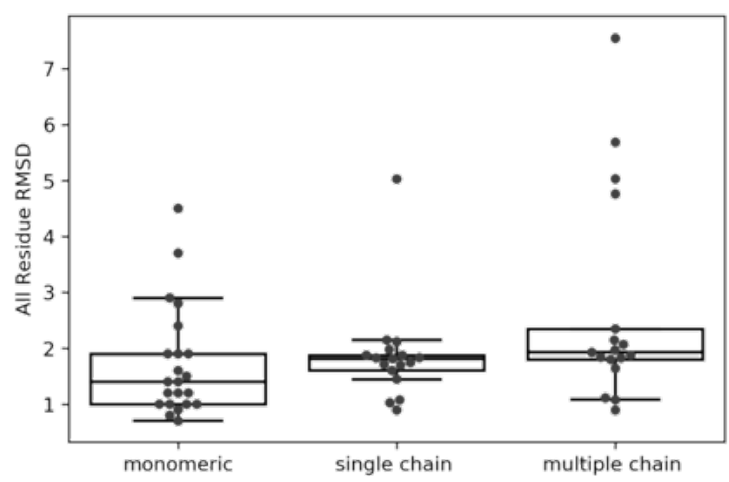

(C)

\begin{tabular}{|c|c|c|c|c|}
\hline All residues & & monomeric & single chain & multiple chain \\
\hline $\begin{array}{c}\text { Models } \\
\text { without catalytic } \\
\text { constraints }\end{array}$ & average & 1.72 & 1.86 & 2.67 \\
\cline { 2 - 5 } & $\begin{array}{c}\text { standard } \\
\text { deviation }\end{array}$ & 0.98 & 0.92 & 1.87 \\
\hline \multirow{2}{*}{$\begin{array}{c}\text { Models } \\
\text { with catalytic } \\
\text { constraints }\end{array}$} & average & 1.58 & 1.83 & 2.64 \\
\cline { 2 - 5 } & standard deviation & 0.91 & 0.83 & 1.82 \\
\hline
\end{tabular}

(B) Models with catalytic constraints All Residue RMSD

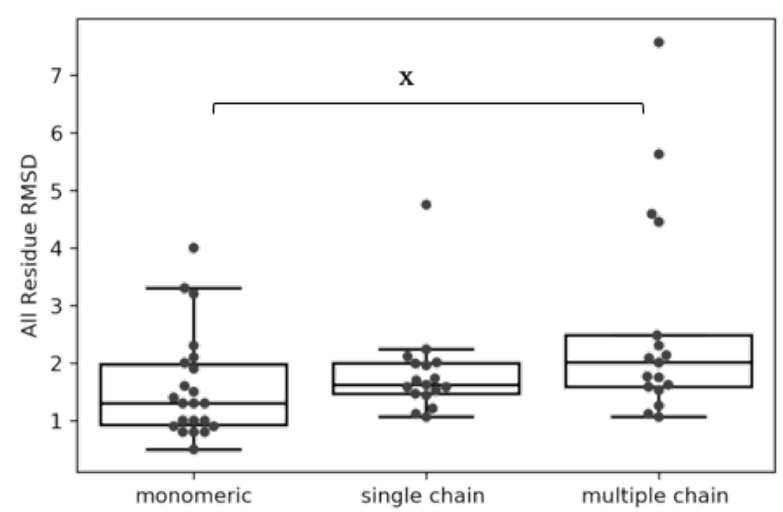

Figure S4. Boxplots comparing the RMSD of all residues between the monomeric and homomeric benchmarks. Each point in (A) and (B) represents the average RMSD of all residues for the lowest five models. The single chain represents the RMSD of only the single chain between the crystal structures or models within the homomeric benchmark. The multiple chains represent the RMSD analysis between all chains of the crystal structures or models within the homomeric benchmark. The $X$ correspond to a p-value $<0.05$. (A) Analysis between the target crystal structure to models without catalytic constraints (B) Analysis between the target crystal structure to models with catalytic constraints (C) A table of the average and standard deviation for the boxplots in A - B 
(A) Models without catalytic constraints Active Site RMSD

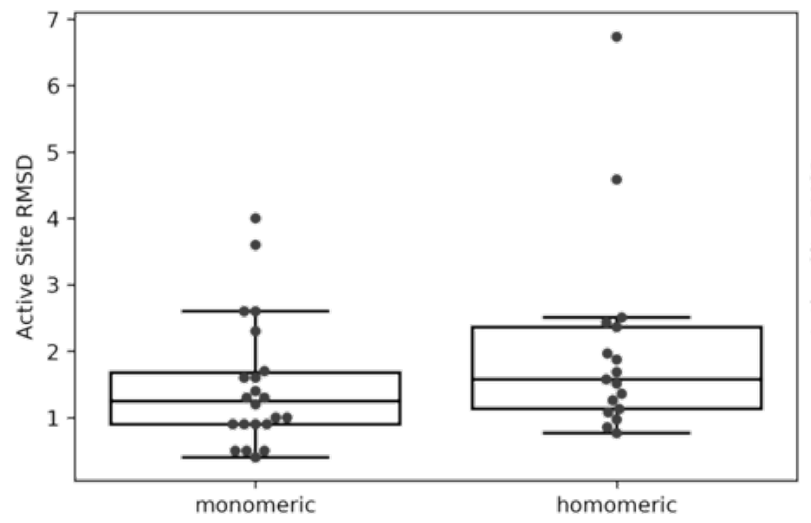

(C)

\begin{tabular}{|c|c|c|c|}
\hline Active site & & monomeric & homomeric \\
\hline Models & average & 1.48 & 2.04 \\
\cline { 2 - 4 } $\begin{array}{c}\text { without catalytic } \\
\text { constraints }\end{array}$ & $\begin{array}{c}\text { standard } \\
\text { deviation }\end{array}$ & 0.97 & 1.51 \\
\hline & average & 1.09 & 2.07 \\
\hline $\begin{array}{c}\text { Models } \\
\text { with catalytic } \\
\text { constraints }\end{array}$ & standard deviation & 0.85 & 1.62 \\
\cline { 2 - 4 }
\end{tabular}

(B) Models with catalytic constraints Active Site RMSD

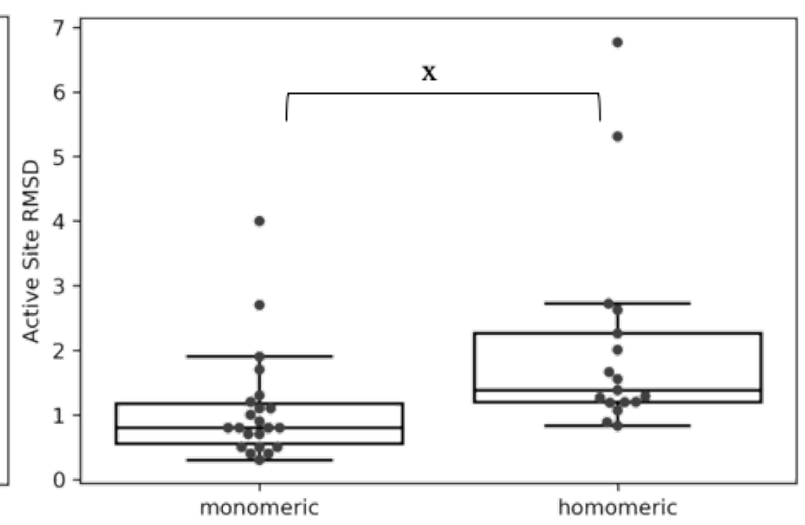

Figure S5. Boxplots comparing the RMSD of all residues between the monomeric and homomeric benchmarks. Each point in (A) and (B) represents the average RMSD of active site residues for the lowest five models. The single chain represents the RMSD of only the single chain between the crystal structures or models within the homomeric benchmark. The multiple chains represents the RMSD analysis between all chains of the crystal structures or models within the homomeric benchmark. The $X$ correspond to a $p$-value $<0.05$. (A) Analysis between the target crystal structure to models without catalytic constraints (B) Analysis between the target crystal structure to models with catalytic constraints $(\mathrm{C})$ A table of the average and standard deviation for the boxplots in $\mathrm{A}-\mathrm{B}$ 
Table S5. Statistical analysis of the all residue and active site RMSD using a two tailed t-test (A) all residues (B) active site residues

(A)

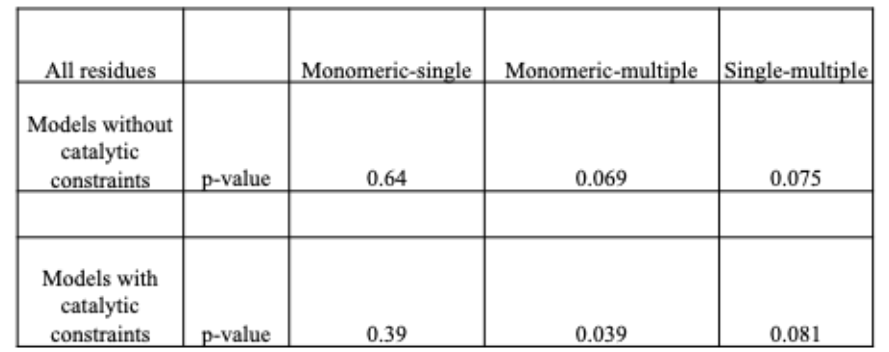

(B)

\begin{tabular}{|c|c|c|}
\hline Active site & & Monomeric-homomeric \\
\hline $\begin{array}{c}\text { Models without } \\
\text { catalytic constraints }\end{array}$ & p-value & 0.20 \\
\cline { 2 - 3 } & & \\
\hline $\begin{array}{c}\text { Models with } \\
\text { catalytic constraints }\end{array}$ & p-value & 0.033 \\
\hline
\end{tabular}

Table S6. Number of conformations

\begin{tabular}{|c|c|}
\hline $\mathrm{pdb}$ & number of rotamers \\
\hline lnki & 1 \\
\hline $3 \mathrm{mng}$ & 3 \\
\hline $1 \mathrm{ovm}$ & 4 \\
\hline $5 \mathrm{nd} 5$ & 4 \\
\hline $1 \mathrm{a} 59$ & 10 \\
\hline $2 \mathrm{vbg}$ & 36 \\
\hline $4 \mathrm{bnp}$ & 81 \\
\hline $1 \mathrm{ctu}$ & 165 \\
\hline 4fua & 243 \\
\hline 3 fuc & 319 \\
\hline $3 \mathrm{fzn}$ & 322 \\
\hline $1 \mathrm{dqx}$ & 1169 \\
\hline 3 bgs & 1455 \\
\hline $2 \mathrm{q} 7 \mathrm{o}$ & 3763 \\
\hline $204 p$ & 20505 \\
\hline 4hgo & 44289 \\
\hline 1qin & 54278 \\
\hline
\end{tabular}


Figure S6 The crystal structure is depicted in a deep purple color with the models overlaid on top. The models are depicted in blue and dark gray. The crystal structure ligand is in a deep purple color and the ligand docked into the model is in a dark gray.

(A) $1 \mathrm{ctu}$
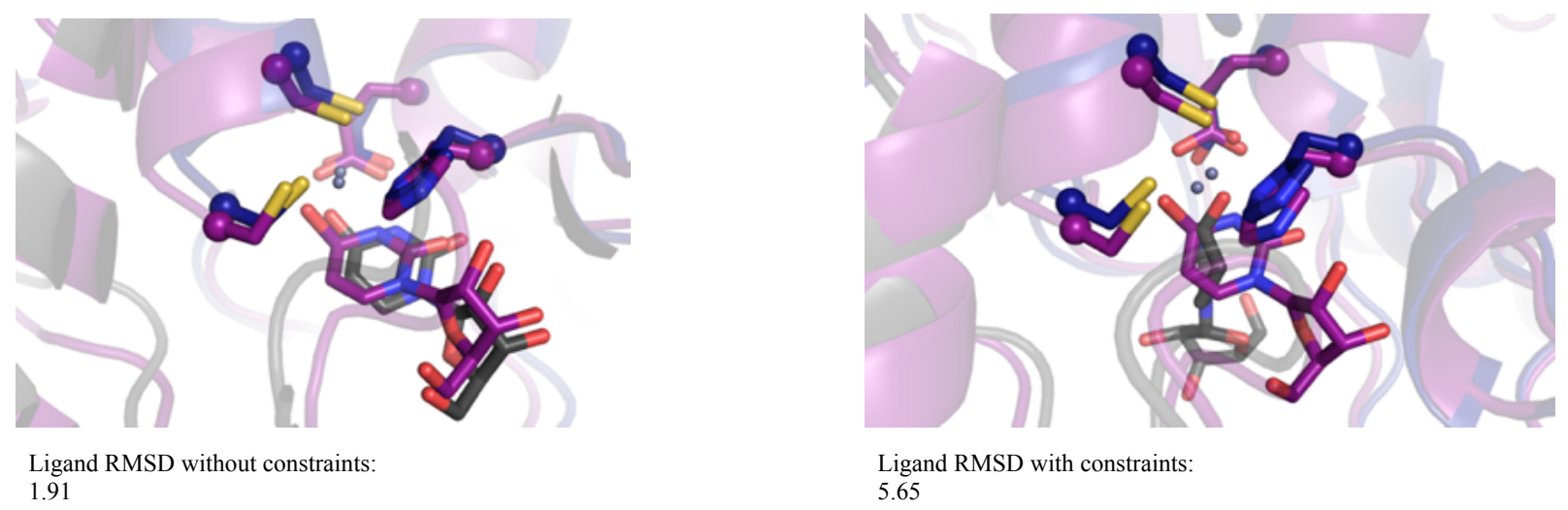

(B) $1 d q x$

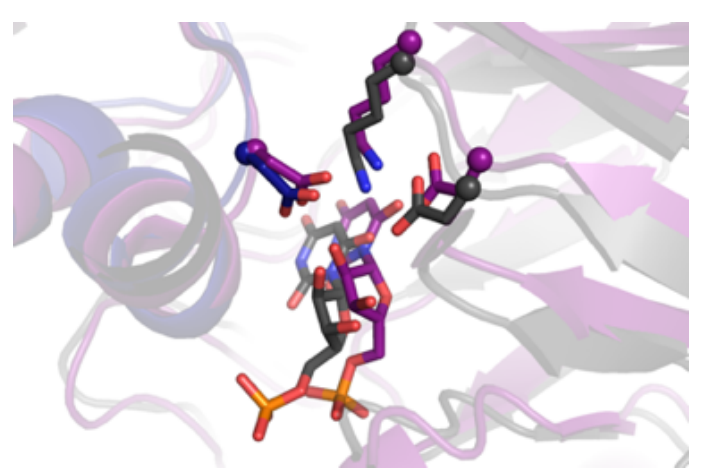

Ligand RMSD without constraints: 3.15

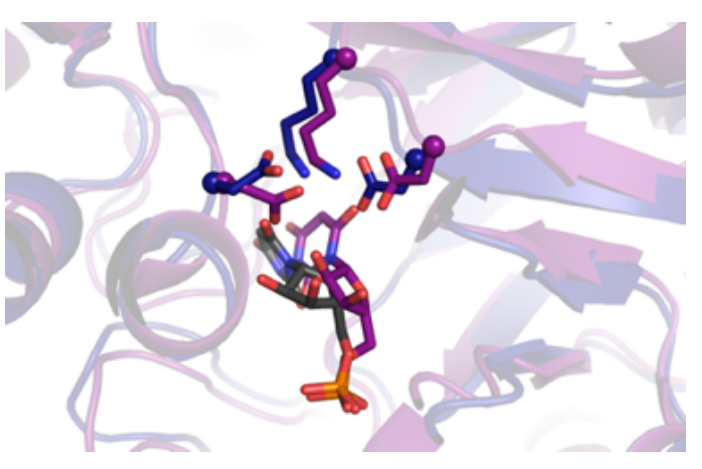

Ligand RMSD with constraints: 5.53 
(C) 1nki

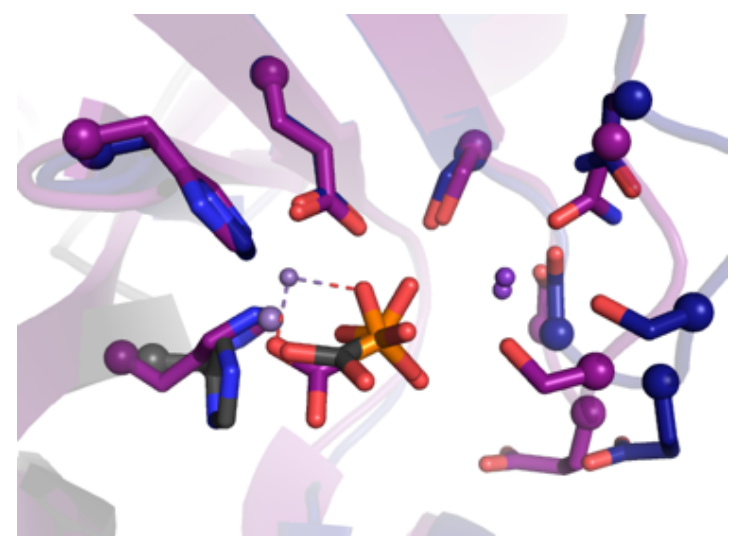

Ligand RMSD without constraints: 2.47

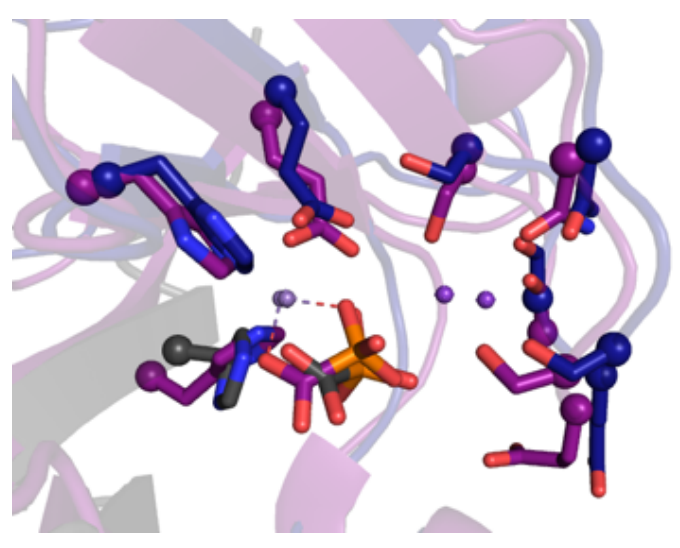

Ligand RMSD with constraints: 2.34

(D) 1ovm

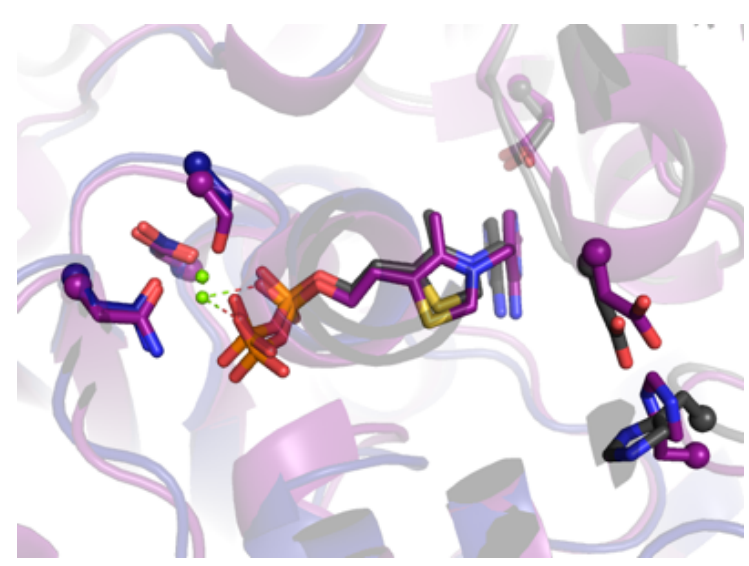

Ligand RMSD without constraints: 1.01

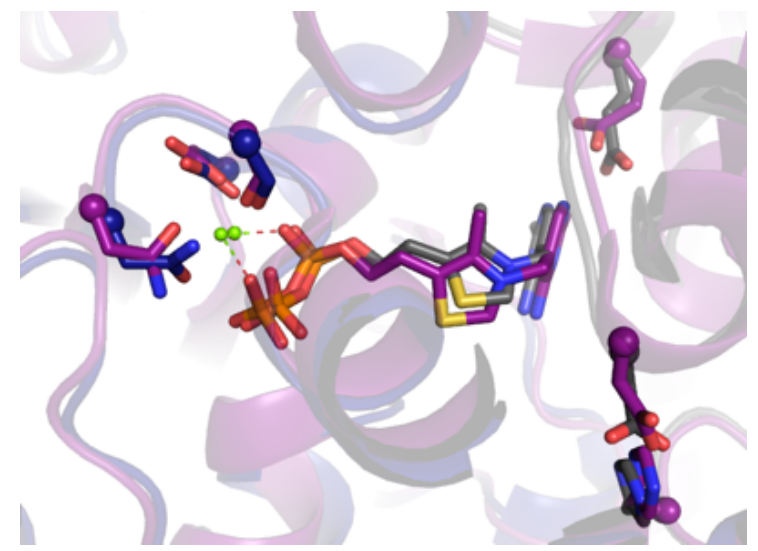

Ligand RMSD with constraints: 1.16 
(E) 1qin

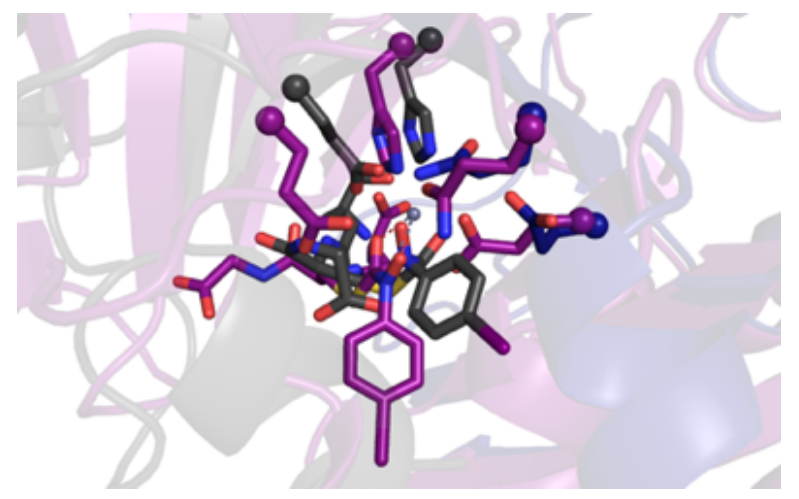

Ligand RMSD without constraints: 6.68

(F) $204 p$

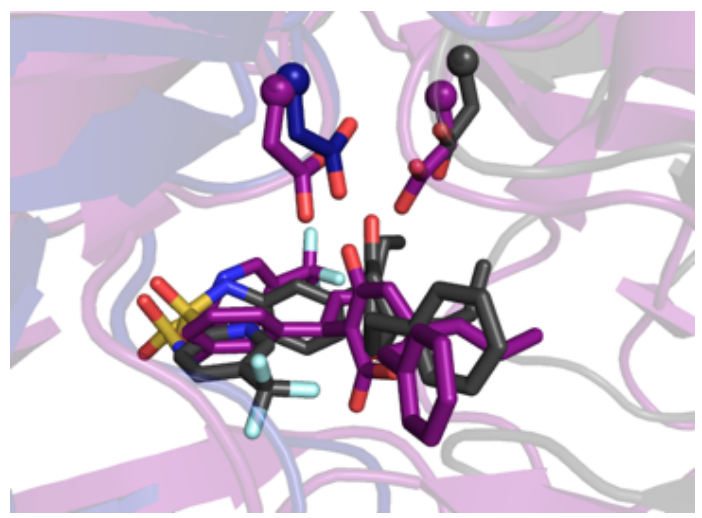

Ligand RMSD without constraints: 10.15

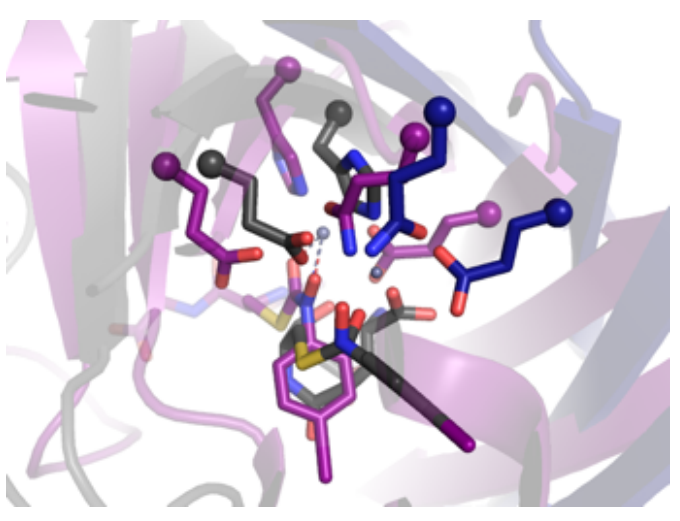

Ligand RMSD with constraints: 8.05

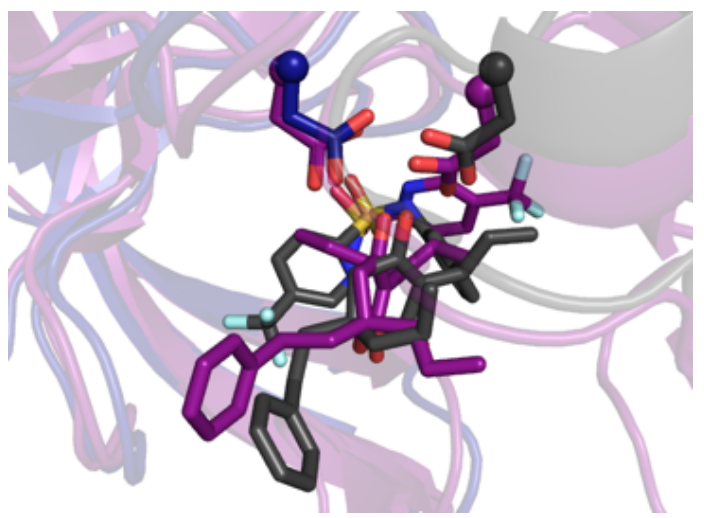

Ligand RMSD with constraints: 9.91 
(G) 2q7o

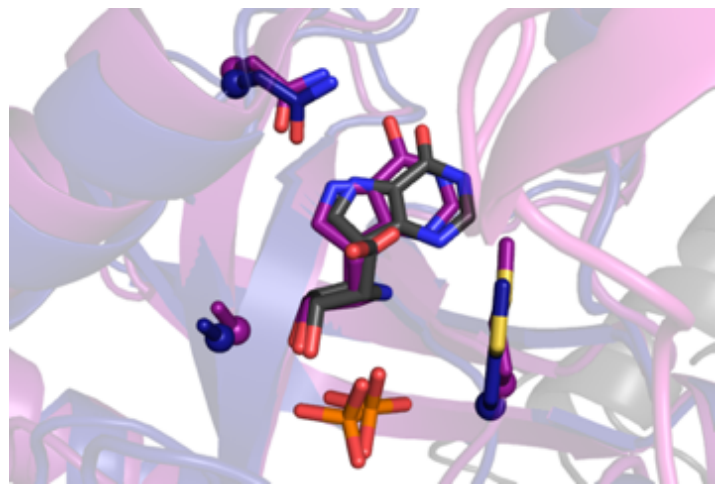

Ligand RMSD without constraints: 1.37

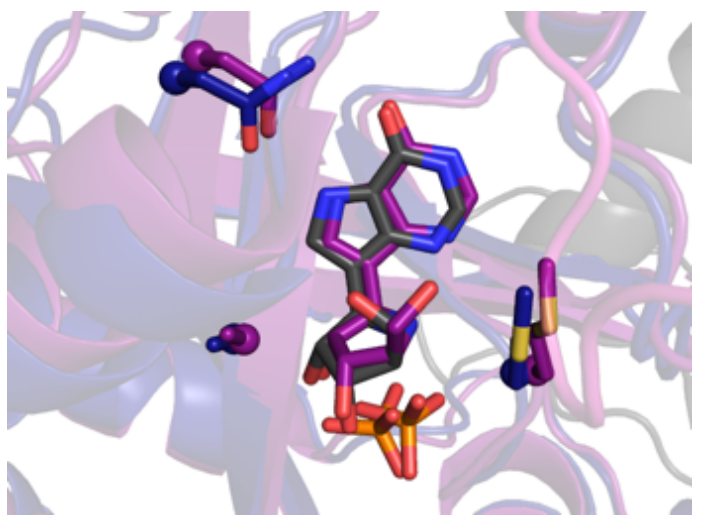

Ligand RMSD with constraints: 1.36

(H) $2 \mathrm{vbg}$

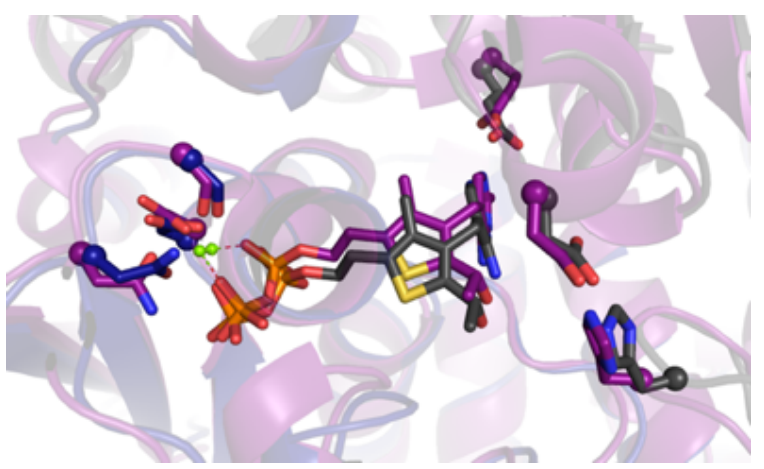

Ligand RMSD without constraints: 1.14

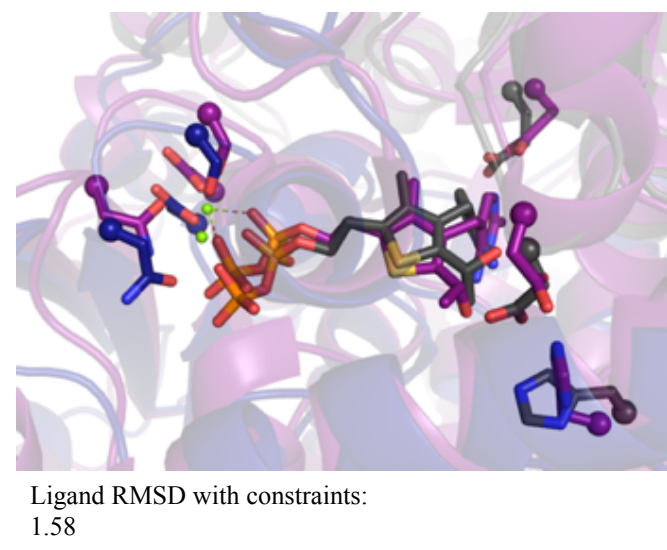


(I) 3 bgs
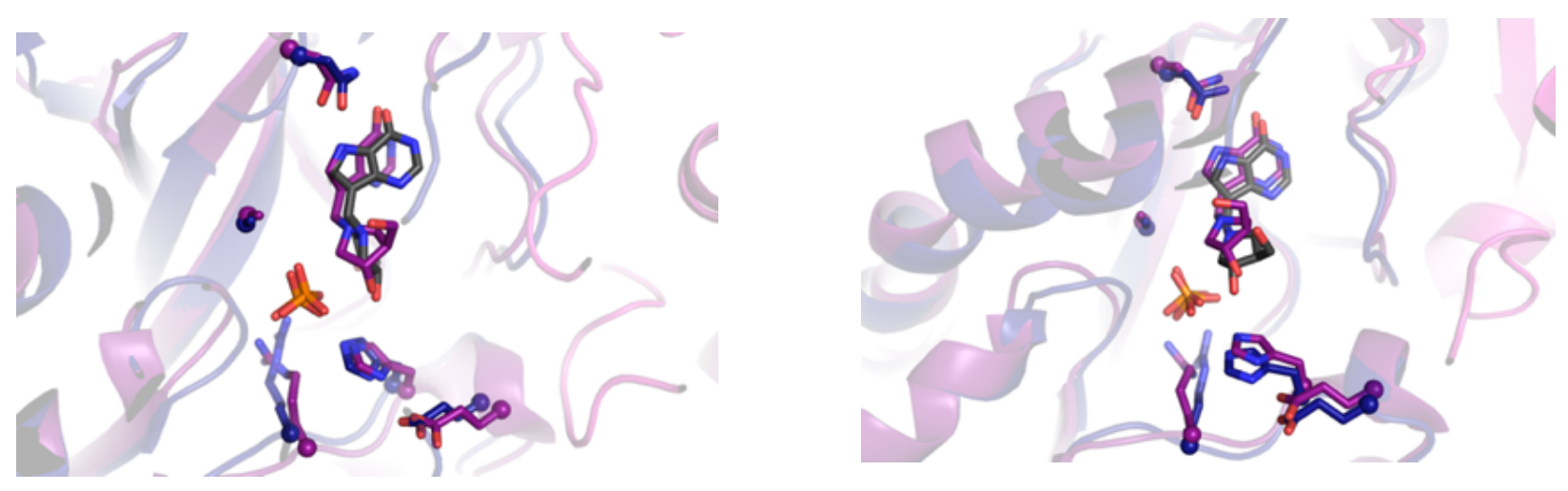

Ligand RMSD without constraints: 3.27

Ligand RMSD with constraints: 1.20

(J) 3 fuc

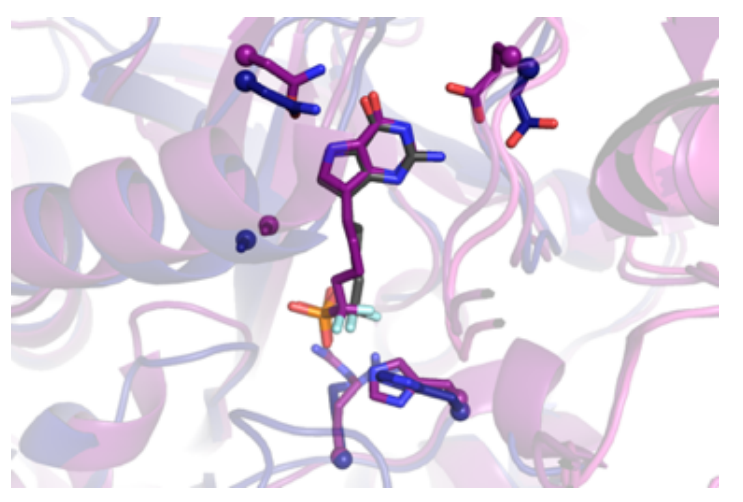

Ligand RMSD without constraints: 2.28

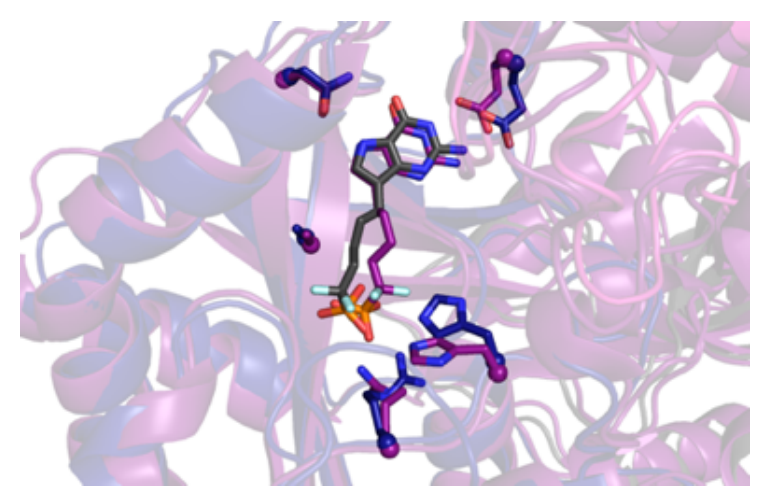

Ligand RMSD with constraints: 1.62 
(K) $3 \mathrm{fzn}$

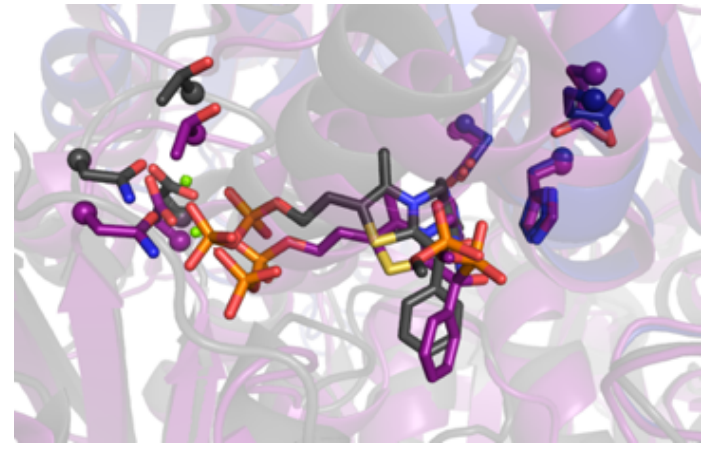

Ligand RMSD without constraints: 3.05

(L) $3 \mathrm{mng}$

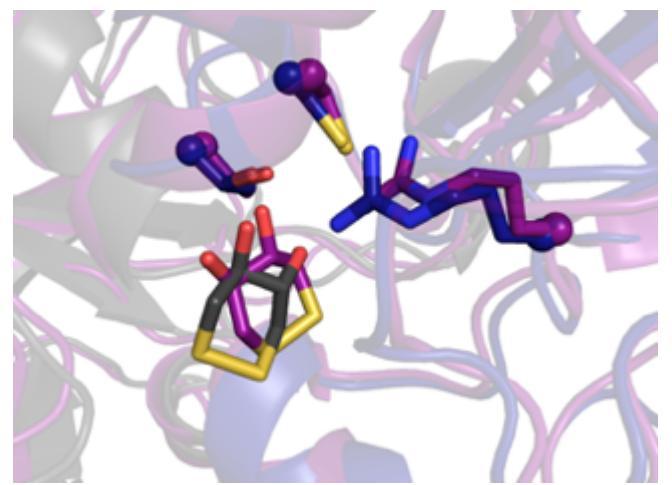

Ligand RMSD without constraints:

2.17

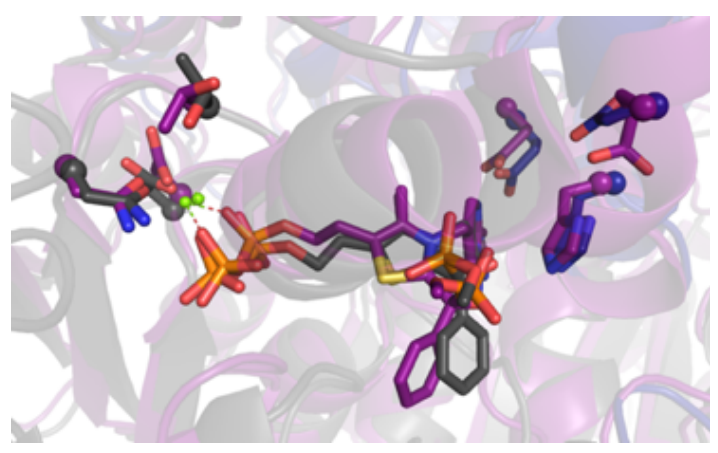

Ligand RMSD with constraints: 2.95

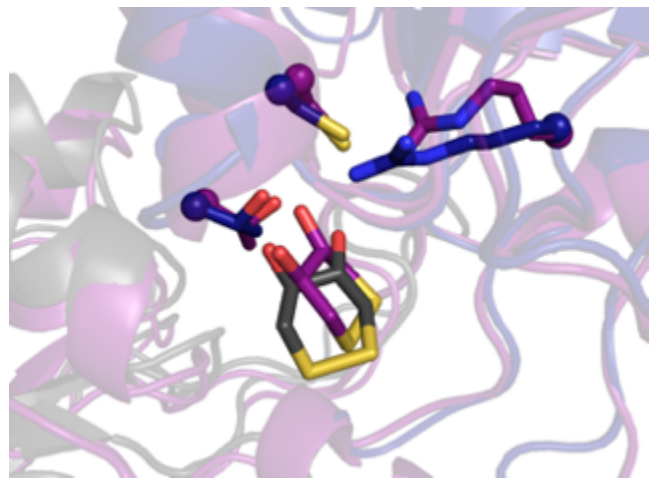

Ligand RMSD with constraints: 1.90 
(M) 4bnp

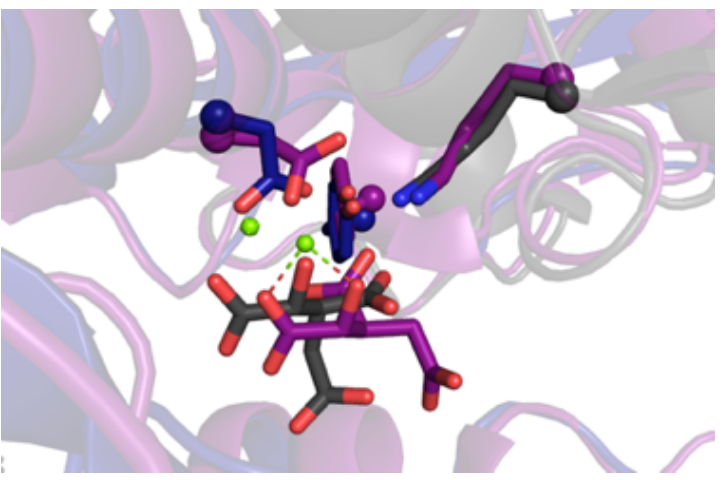

Ligand RMSD without constraints: 2.69

(N) 4fua

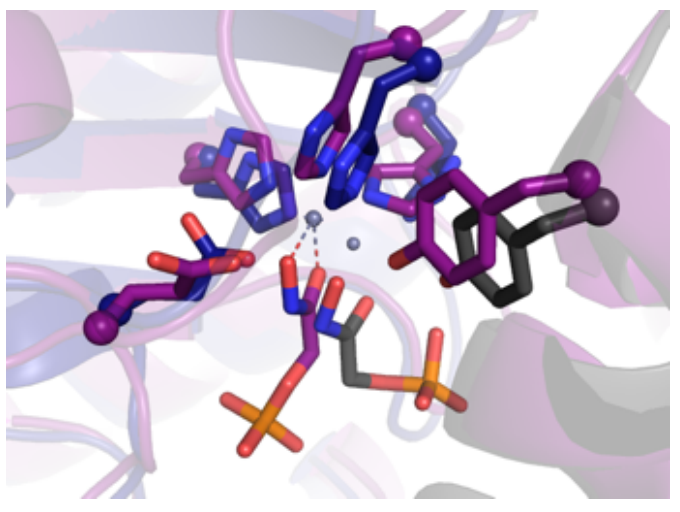

Ligand RMSD without constraints: 3.71

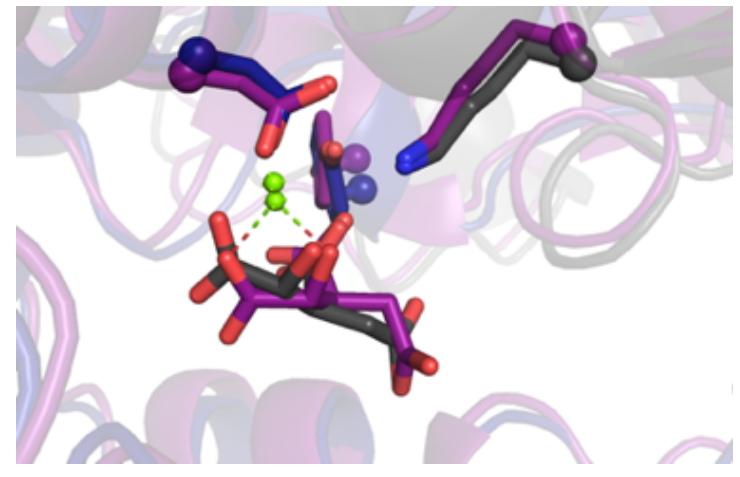

Ligand RMSD with constraints: 1.76

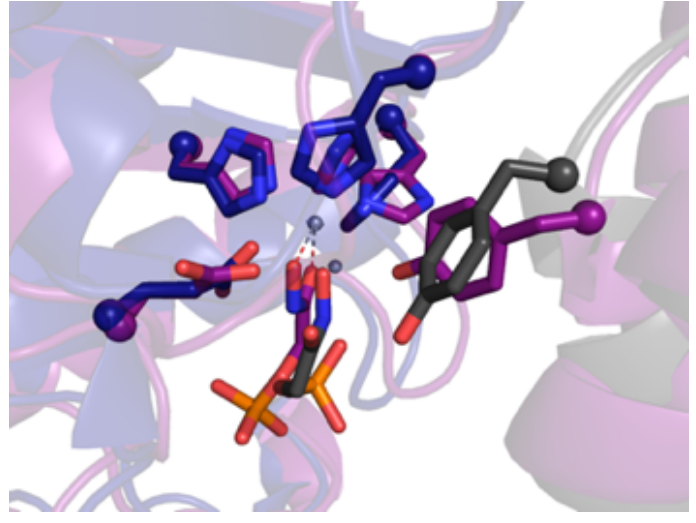

Ligand RMSD with constraints: 3.96 
(O) 4hgo

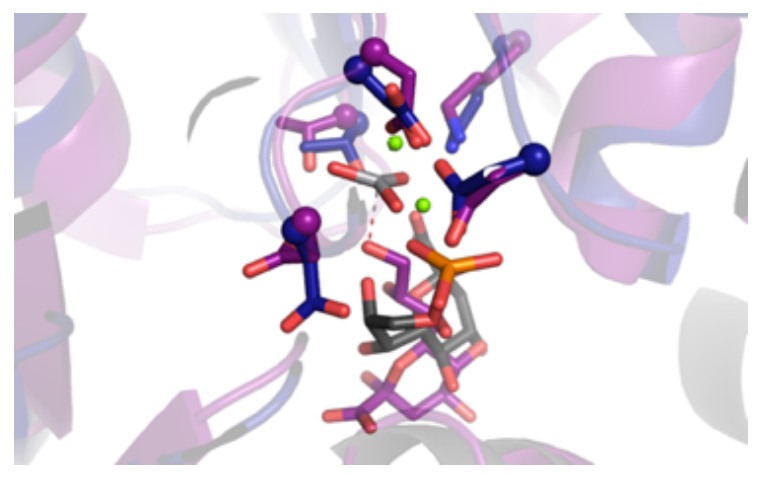

Ligand RMSD without constraints:

6.10

(P) 5nd5

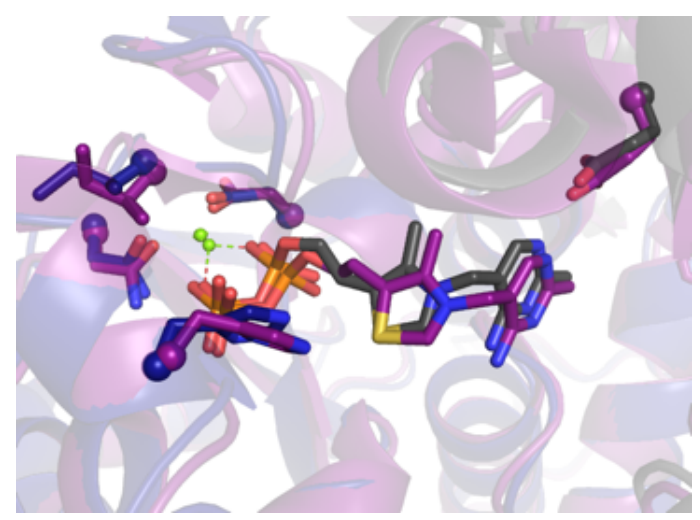

Ligand RMSD without constraints:

1.34

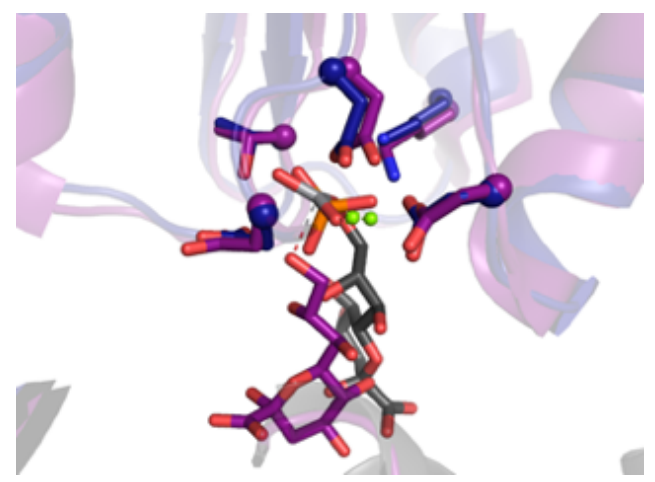

Ligand RMSD with constraints: 5.60

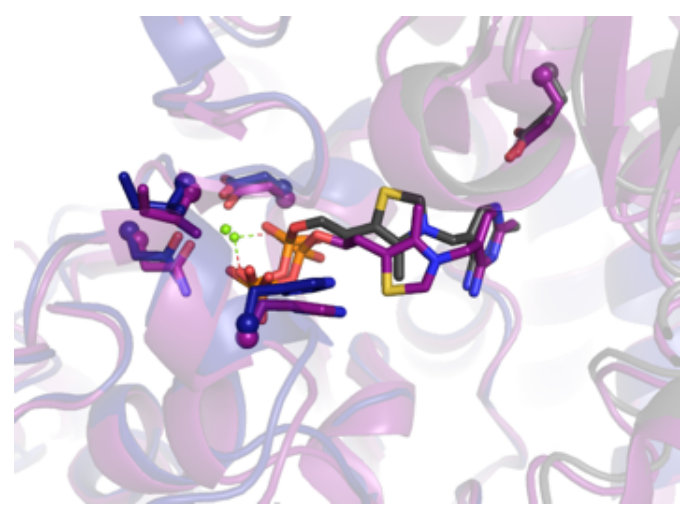

Ligand RMSD with constraints: 1.51 
(Q) $1 \mathrm{a} 59$

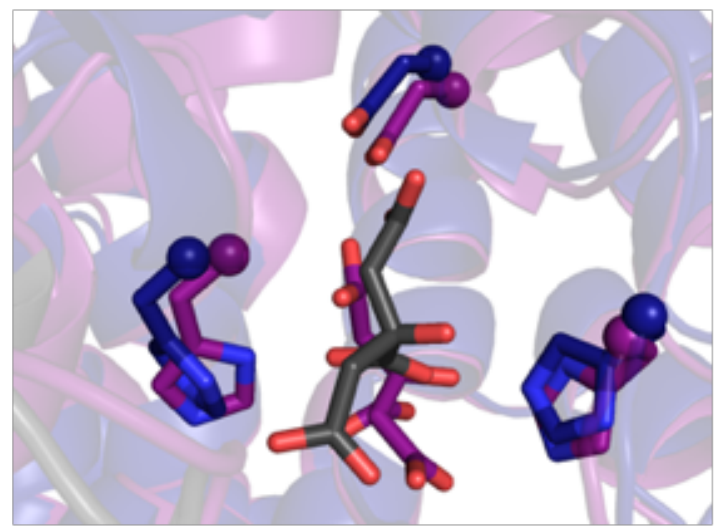

Ligand RMSD without constraints: 3.37

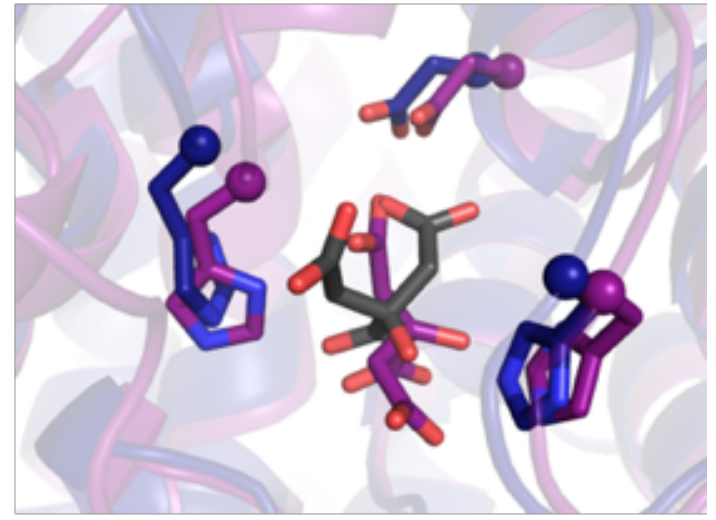

Ligand RMSD with constraints: 3.07

Figure S7 The area of the active site highlighted with a red circle on the first cartoon representation of protein. The crystal structure is depicted in a deep purple color with the models overlaid on top in cartoon and ribbon form. Depending on the number of chains, the models are depicted in blue (chain A), dark gray (chain B), light blue (chain C), and light gray (chain D).

(a) 1 ctu
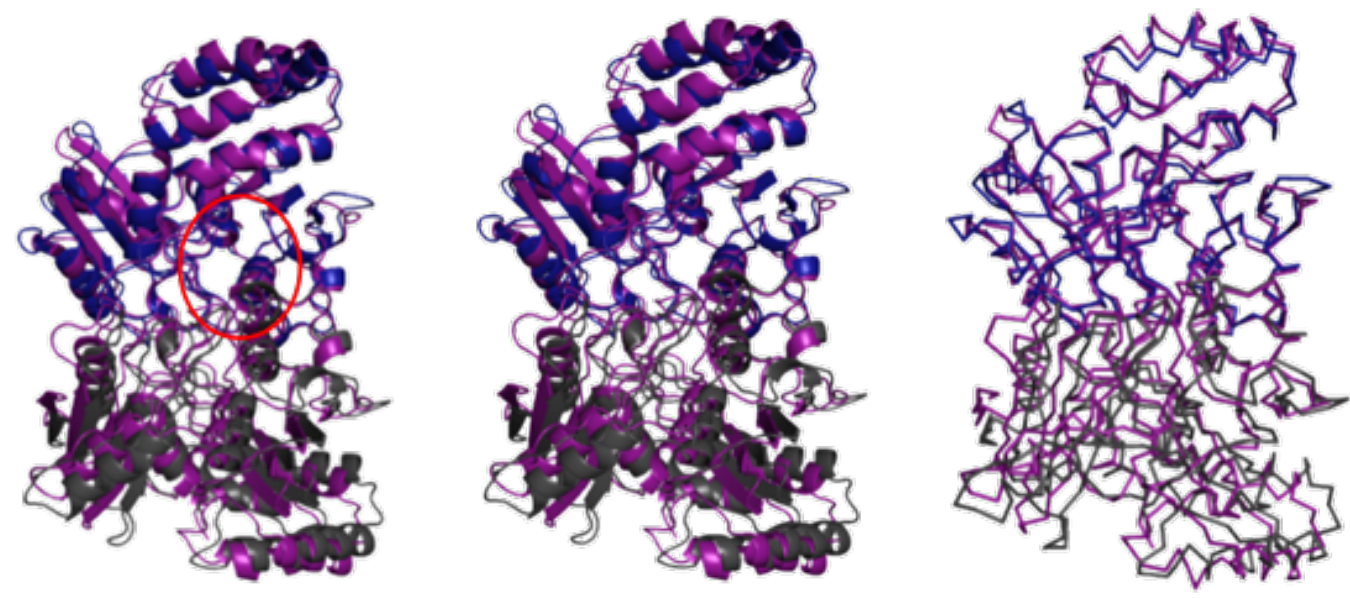
(b) 1dqx
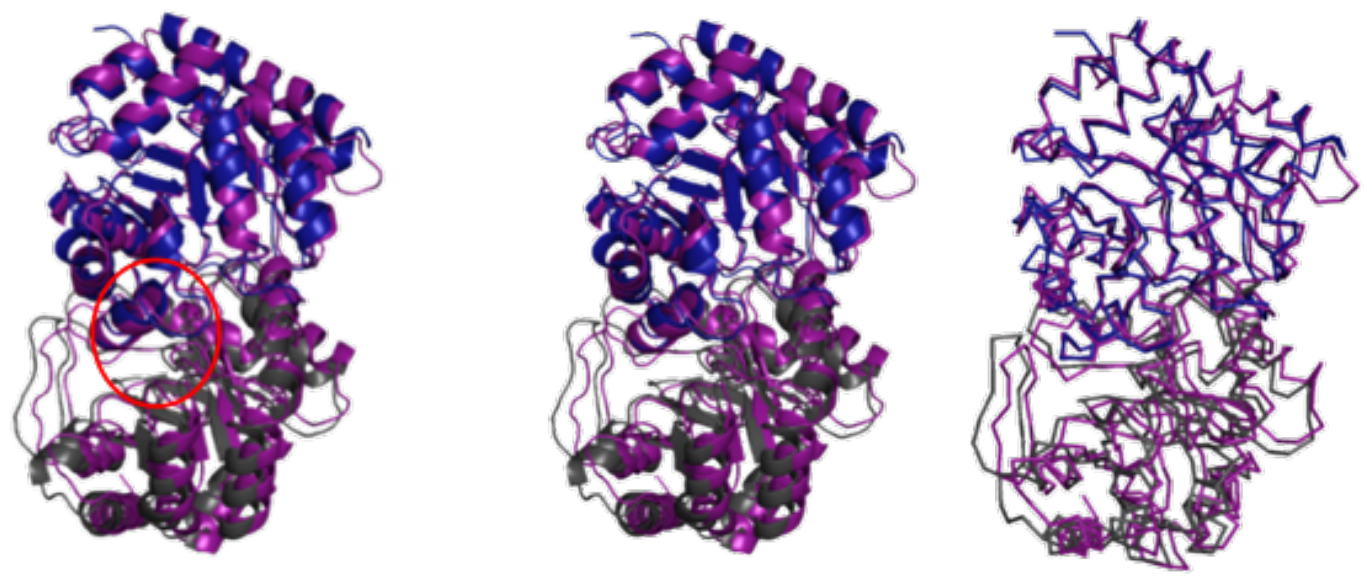

(c) 1nki
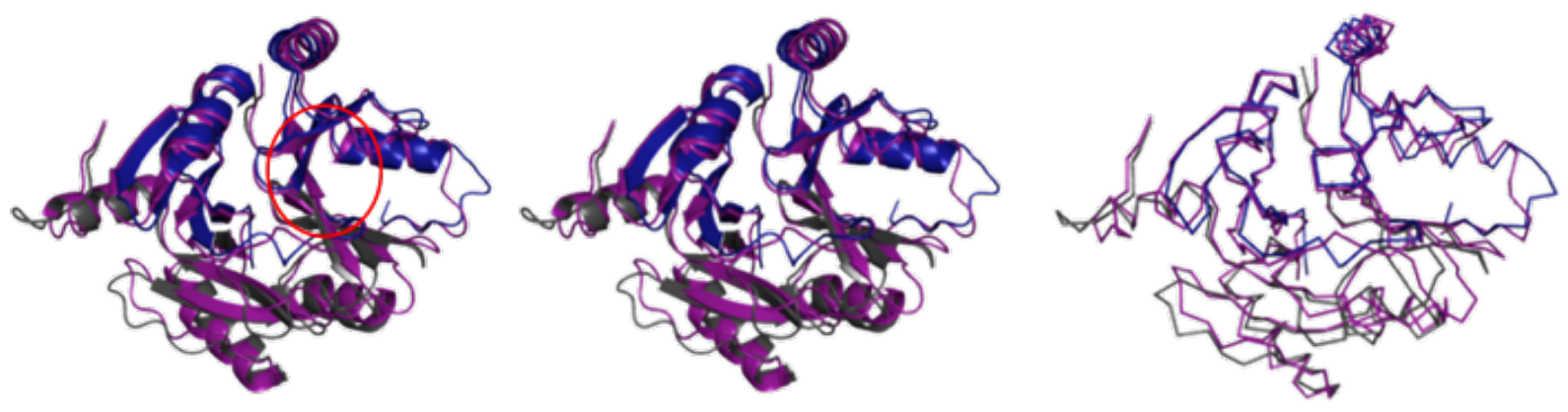

(d) $1 \mathrm{ovm}$
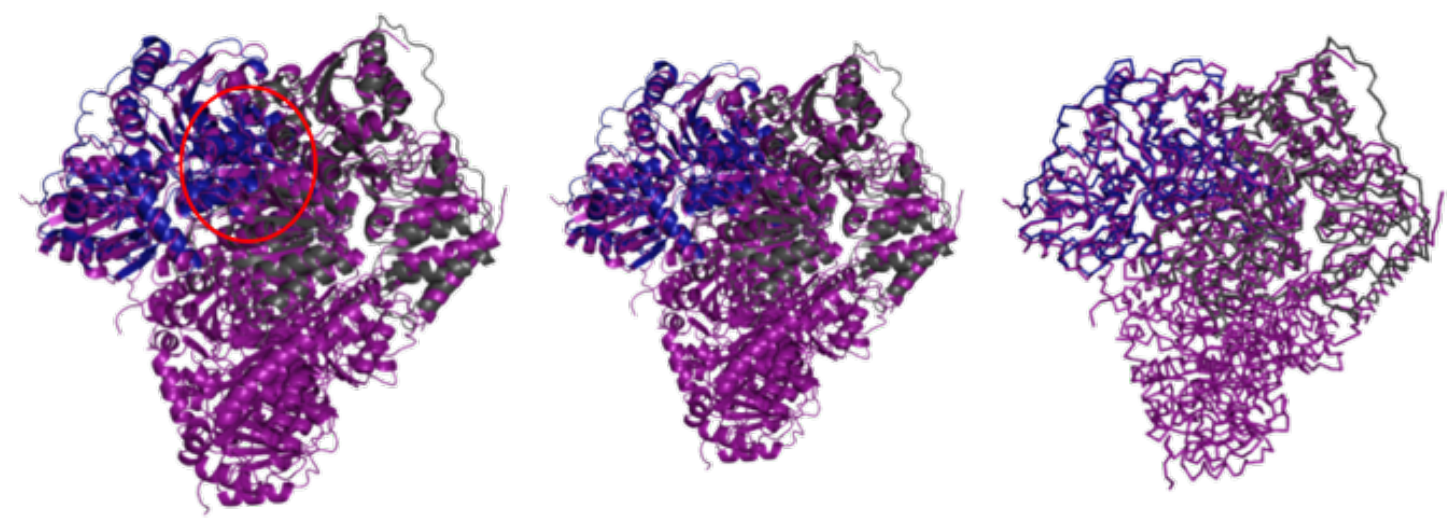
(e) 1qin
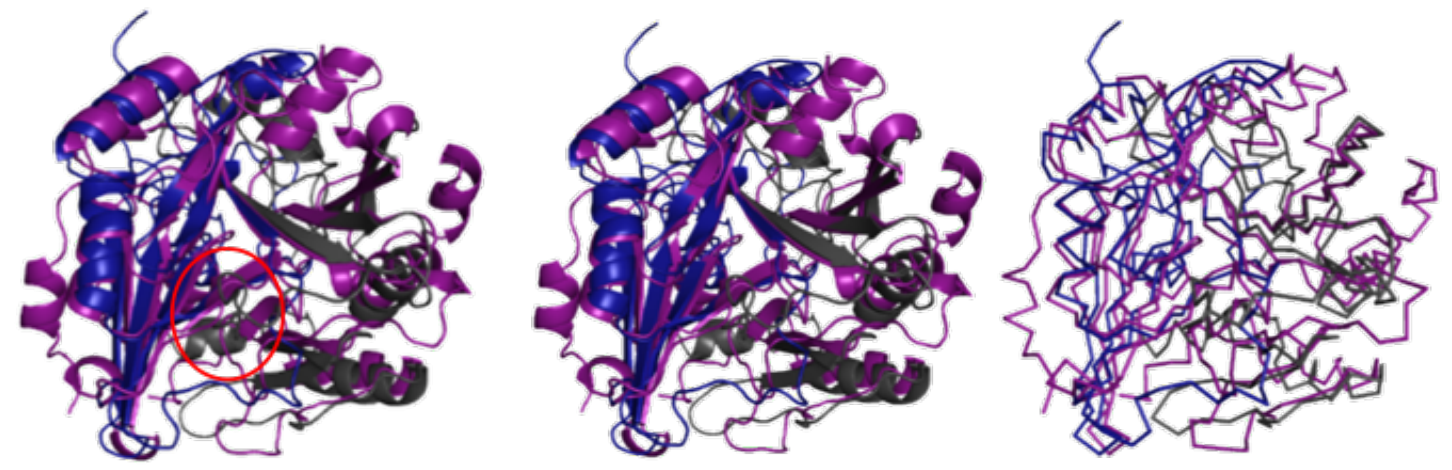

(f) $1 \mathrm{a} 59$
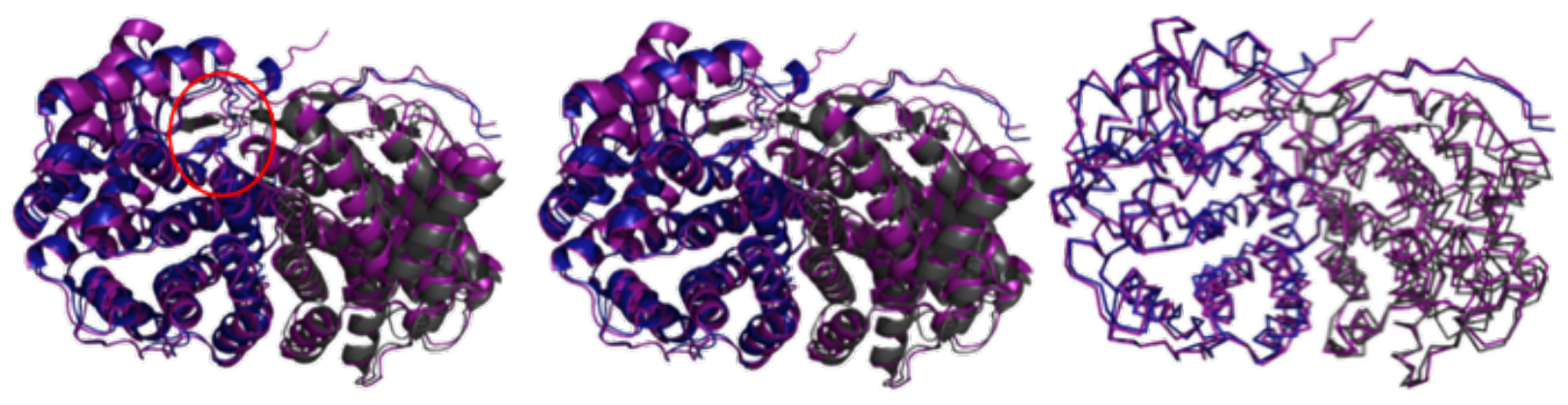

(g) $2 o 4 p$
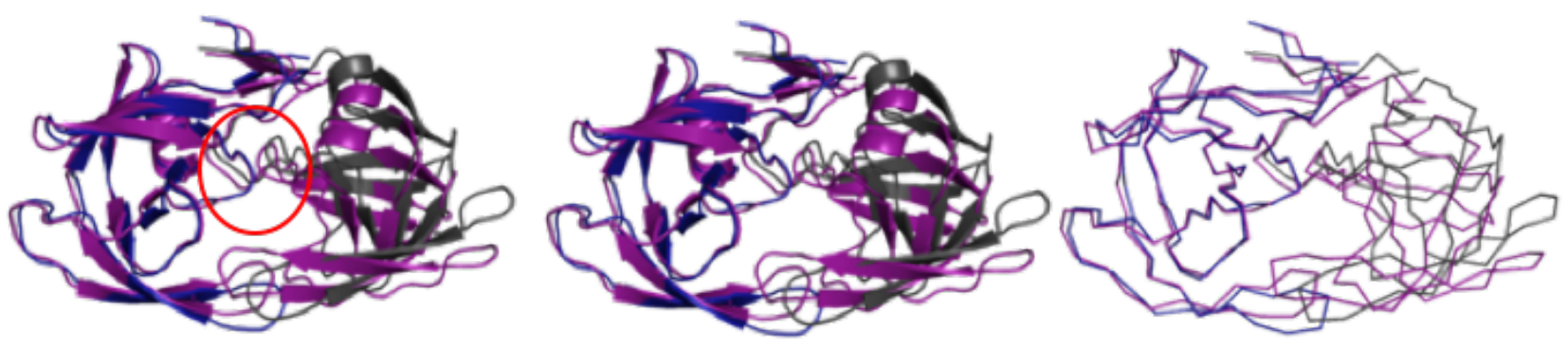
(h) $2 q 7 o$
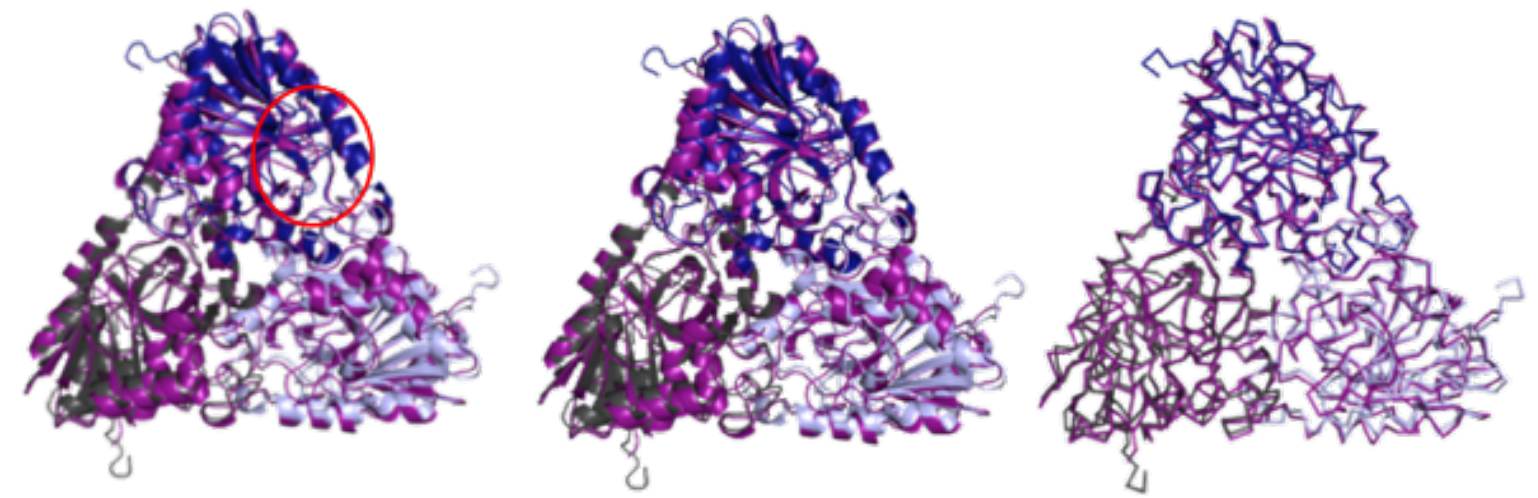

(i) $2 \mathrm{vbg}$
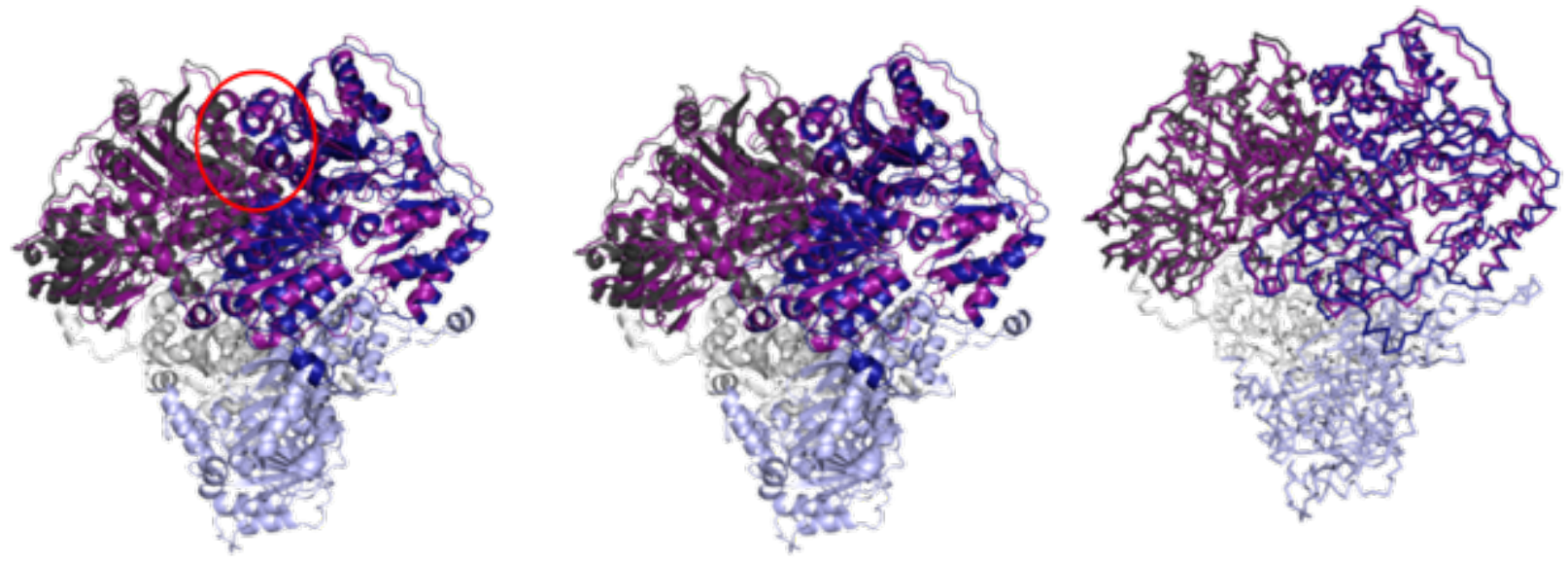

(j) $3 \mathrm{bgs}$
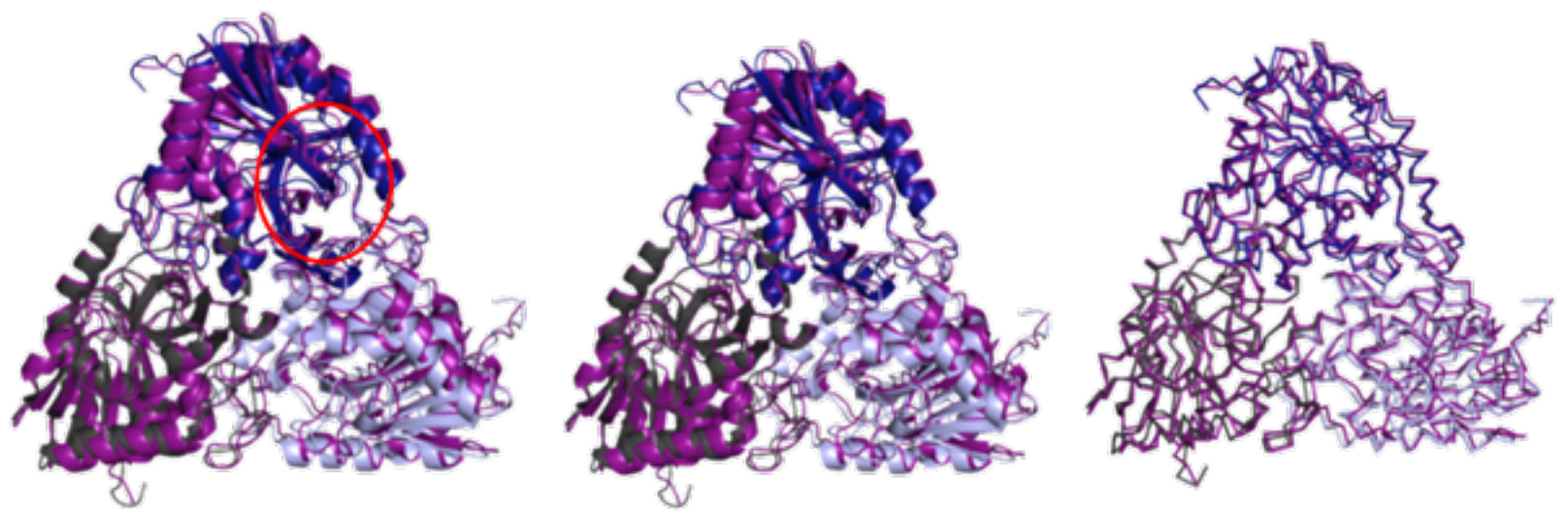
(k) 3 fuc
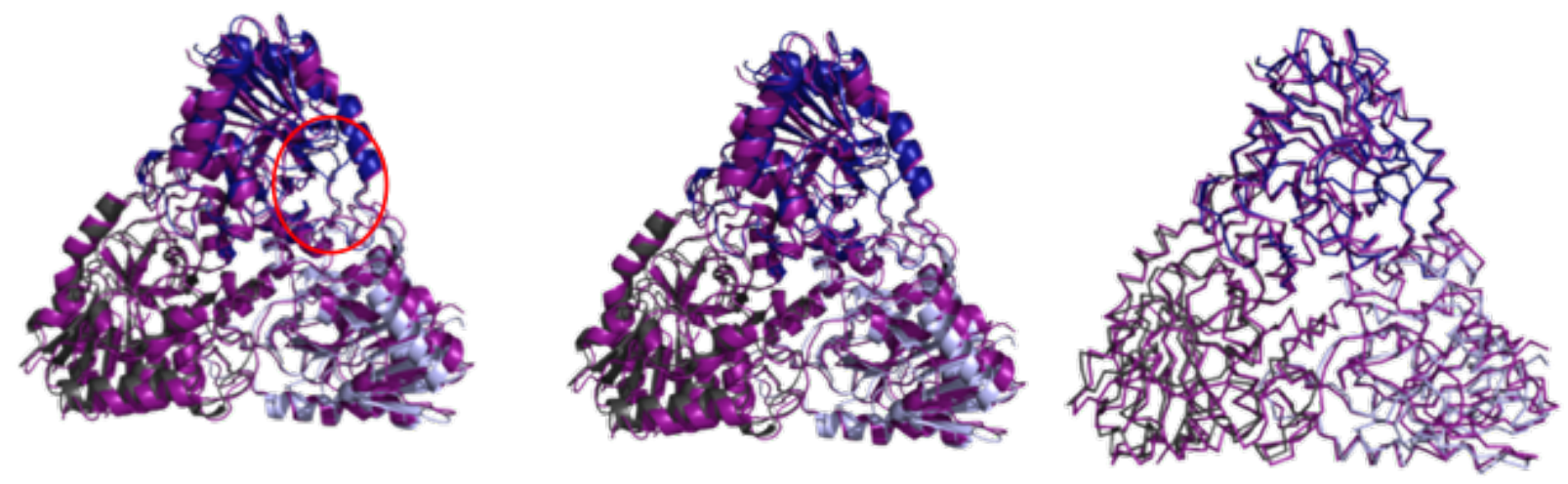

(1) $3 \mathrm{fzn}$
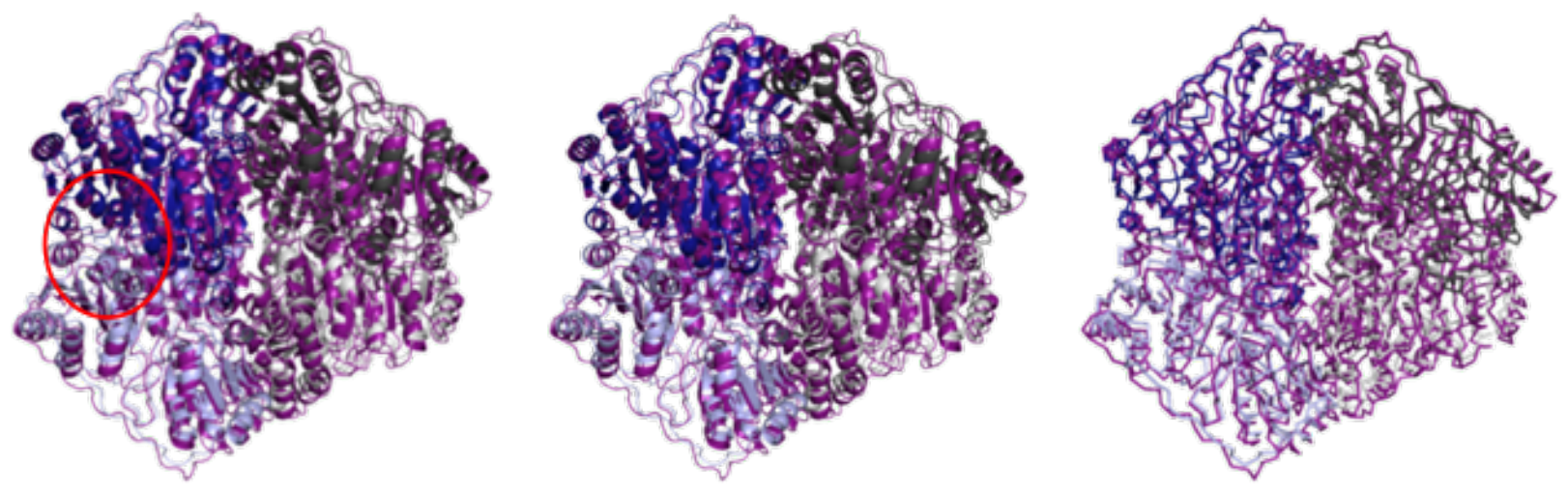

(m) 3mng
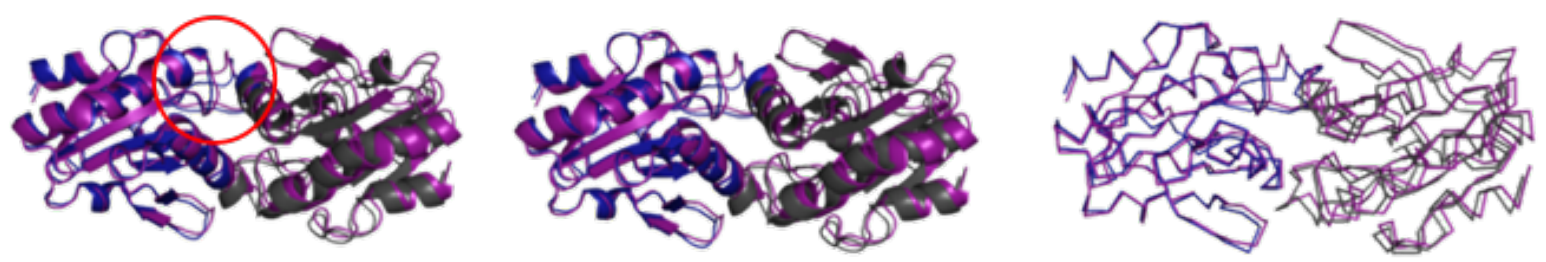
(n) 4 bnp
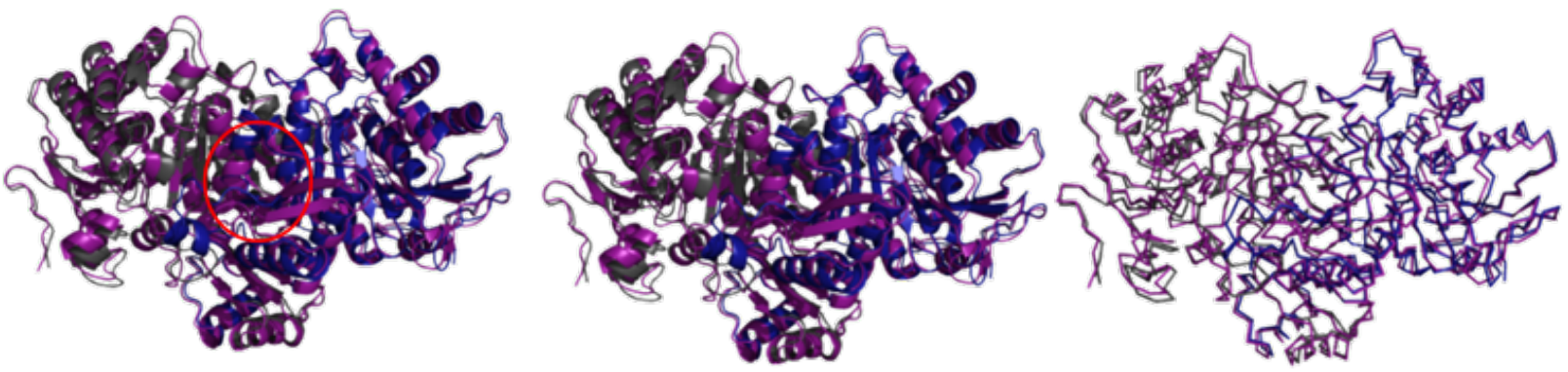

(o) 4fua
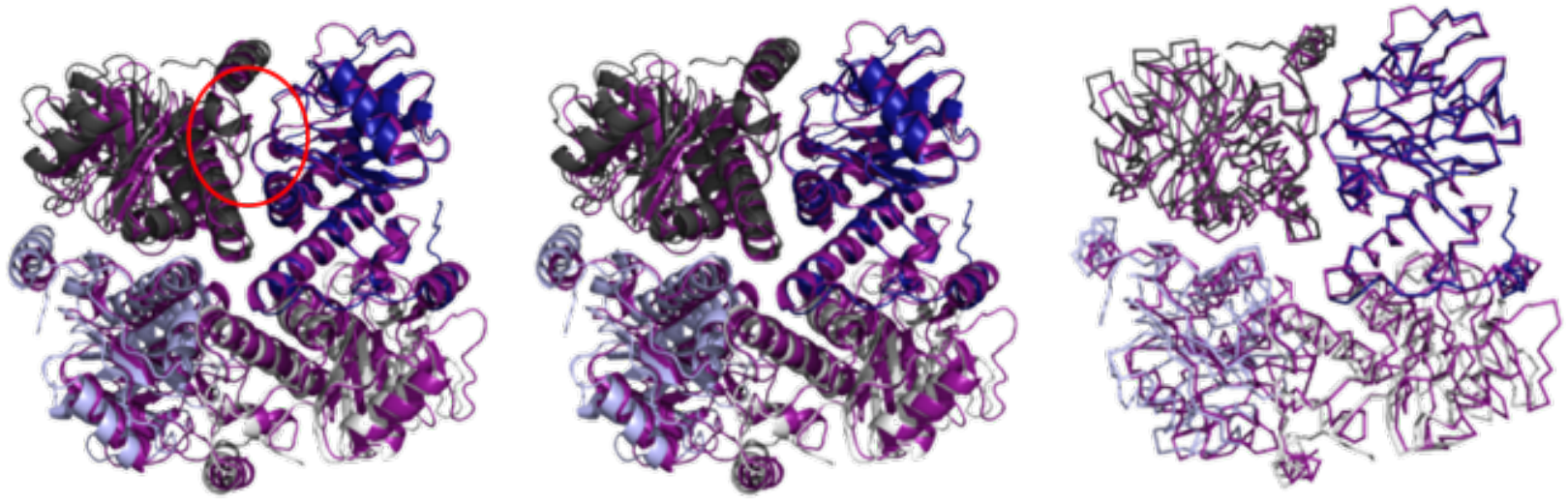

(p) 4hgo
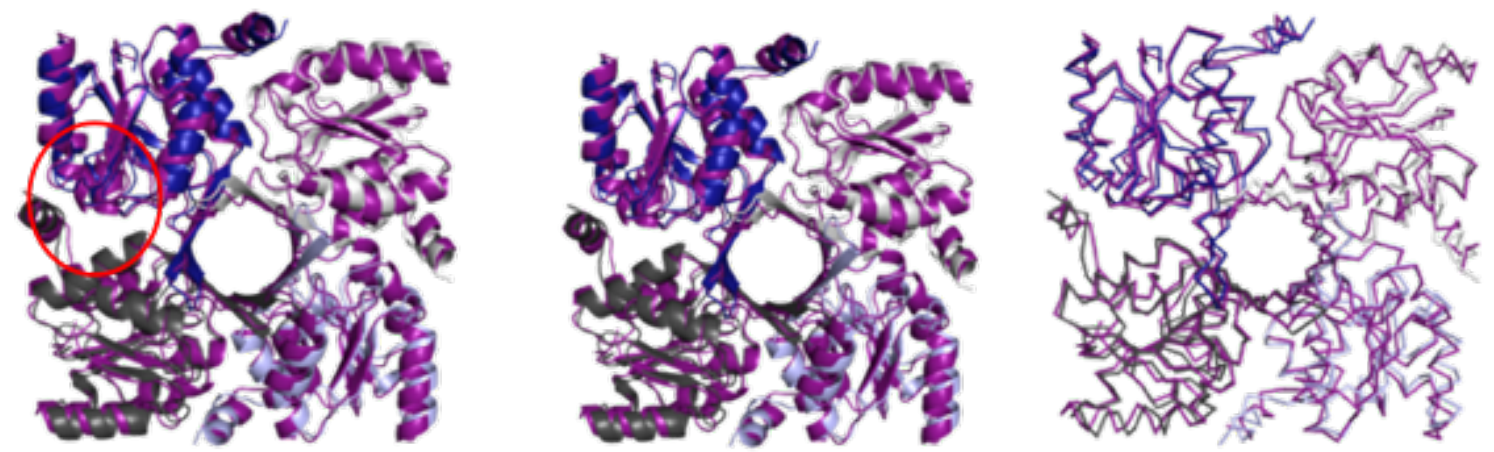
(q) $5 \mathrm{nd} 5$
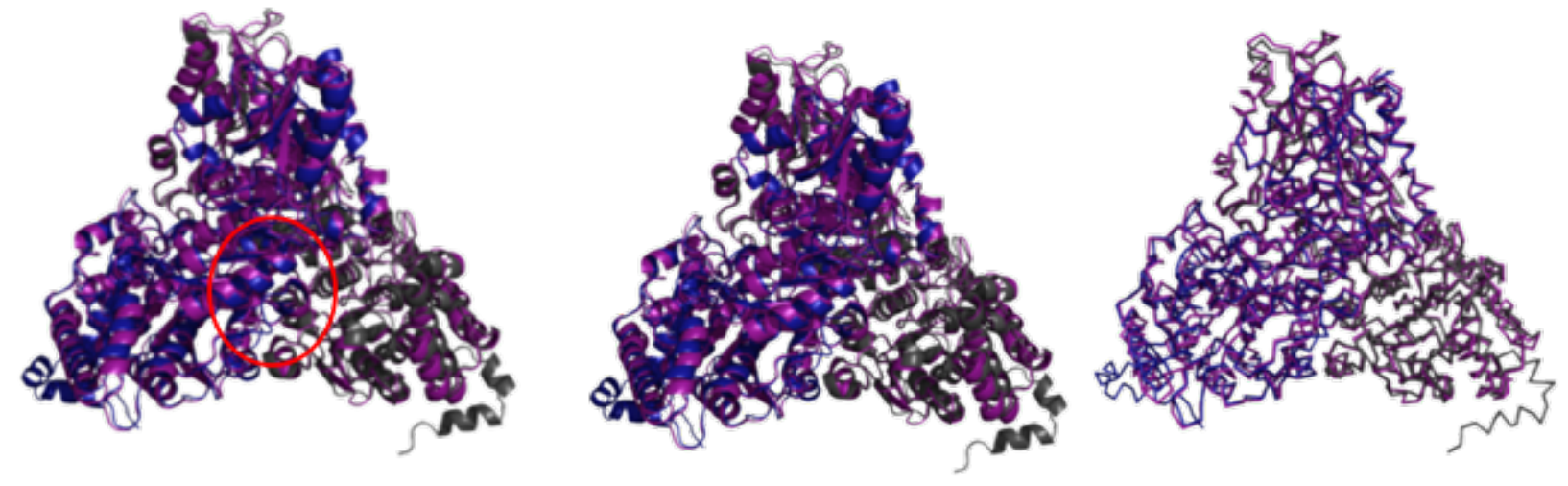